\title{
Review
}

\section{Remote Healthcare for Elderly People Using Wearables: A Review}

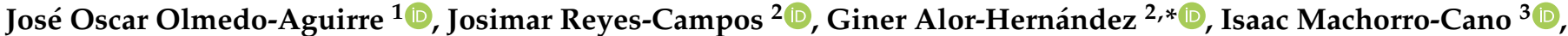 \\ Lisbeth Rodríguez-Mazahua ${ }^{2}{ }^{\mathbb{C}}$ and José Luis Sánchez-Cervantes ${ }^{4} \mathbb{C}$
}

Citation: Olmedo-Aguirre, J.O.; Reyes-Campos, J.; Alor-Hernández, G.; Machorro-Cano, I.;

Rodríguez-Mazahua, L.;

Sánchez-Cervantes, J.L. Remote

Healthcare for Elderly People Using

Wearables: A Review. Biosensors 2022,

12, 73. https://doi.org/10.3390/

bios12020073

Received: 23 December 2021

Accepted: 25 January 2022

Published: 27 January 2022

Publisher's Note: MDPI stays neutral with regard to jurisdictional claims in published maps and institutional affiliations.

Copyright: (c) 2022 by the authors. Licensee MDPI, Basel, Switzerland. This article is an open access article distributed under the terms and conditions of the Creative Commons Attribution (CC BY) license (https:// creativecommons.org/licenses/by/ $4.0 /)$.
1 Department of Electrical Engineering, CINVESTAV-IPN, Av. Instituto Politécnico Nacional 2 508, Col. San Pedro Zacatenco, Delegación Gustavo A. Madero, Mexico City C.P. 07360, Mexico; oolmedo@cinvestav.mx

2 Tecnológico Nacional de México/I. T. Orizaba, Av. Oriente 9 852, Col. Emiliano Zapata, Orizaba C.P. 94320, Veracruz, Mexico; josi.reyescampos@gmail.com (J.R.-C.); lrodriguezm@ito-depi.edu.mx (L.R.-M.)

3 Universidad del Papaloapan, Circuito Central \#200, Col. Parque Industrial, Tuxtepec C.P. 68301, Oaxaca, Mexico; imachorro@unpa.edu.mx

4 CONACYT-Tecnológico Nacional de México/I. T. Orizaba, Av. Oriente 9 852, Col. Emiliano Zapata, Orizaba C.P. 94320, Veracruz, Mexico; jlsanchez@conacyt.mx

* Correspondence: giner.ah@orizaba.tecnm.mx; Tel./Fax: +52-272-725-7056

\begin{abstract}
The growth of health care spending on older adults with chronic diseases faces major concerns that require effective measures to be adopted worldwide. Among the main concerns is whether recent technological advances now offer the possibility of providing remote health care for the aging population. The benefits of suitable prevention and adequate monitoring of chronic diseases by using emerging technological paradigms such as wearable devices and the Internet of Things (IoT) can increase the detection rates of health risks to raise the quality of life for the elderly. Specifically, on the subject of remote health monitoring in older adults, a first approach is required to review devices, sensors, and wearables that serve as tools for obtaining and measuring physiological parameters in order to identify progress, limitations, and areas of opportunity in the development of health monitoring schemes. For these reasons, a review of articles on wearable devices was presented in the first instance to identify whether the selected articles addressed the needs of aged adults. Subsequently, the direct review of commercial and prototype wearable devices with the capability to read physiological parameters was presented to identify whether they are optimal or usable for health monitoring in older adults.
\end{abstract}

Keywords: elderly; healthcare; monitoring; sensors; wearables

\section{Introduction}

Health issues are of fundamental concern for any sector of the population. However, despite the enormous efforts made to improve the detection, diagnosis, and treatment of diseases, there are areas of opportunity in those efforts carried out specifically for the elderly. Older adults are more susceptible to suffering from some type of chronic degenerative disease. Of course, there is also the risk that they will suffer more consequences by presenting non-chronic diseases considered milder for the rest of the population. It is worth mentioning that older adults represent a significant population sector since, in the last United Nations report on the aging of the world population in 2020, approximately 727 million people were aged 65 or over. Furthermore, it is expected that by the year 2050, the population of older adults will increase to approximately 1.5 billion people [1], which implies a significant economic impact on the public and personal finances of various sectors of society. Of course, the growth in economic spending on health care for older adults has a more significant impact in developing countries. In fact, in recent years, more people have been increasingly affected by chronic disorders, mainly due to the increase in the elderly 
population [2]. Some diseases with the highest incidence within this population sector are cardiovascular diseases, diabetes, cancer, and dementia [3].

According to the National Institute of Geriatrics of the Mexican Republic, the main reason for the loss of years of healthy life in older adults is the suffering of chronic degenerative diseases that are, in addition, the primary cause of death worldwide. In the latest statistical report published by the National Institute of Geriatrics of Mexico [4], it was estimated that the major causes of diseases in people aged 60 and over in the world correspond to:

- Cardiovascular diseases (30.3 percent);

- Cancer (15.1 percent);

- Chronic lung diseases (9.5 percent);

- Musculoskeletal diseases (7.5 percent);

- Mental disorders and diseases of the nervous system (6.6 percent).

It is imperative to monitor the health conditions of people at risk of suffering or who are already suffering from these diseases. The negative impact of these diseases is not limited to affecting the physical integrity of patients but also causes a series of secondary problems that affect the emotional and economic state of the patients themselves or even their relatives. On the contrary, there are many cases where the patient's life is put at risk due to some side effects derived from any of the conditions. For example, there is a percentage of deaths in older adults caused by falls, which in turn can be identified as a collateral consequence of dementia or heart disease [5]. On the other hand, there is also the risk that the disease puts the patient's life at serious risk, such as cases of premature death in the elderly associated with diabetes [6].

Although most of the ailments of older adults are caused by chronic diseases, the study results presented here are equally valid in other sectors of the population with the same ailments. Moreover, as older adults are a particularly vulnerable group with severe physical and economic limitations that drastically reduce their self-sufficiency, paying attention to this group is necessary because of their greater dependence on others such as family and friends. Though humane relationships undoubtedly promote health, there are also drawbacks such as the availability of sufficient time, knowledge, attention, and discipline necessary to follow the medical treatment that includes monitoring relevant physiological variables. For these reasons, it is crucial to determine whether the current technology of wearable devices and IoT can help effectively and reliably reduce this dependency while achieving better clinical quality in monitoring the patient's biomedical variables. In the literature, there are already works that have reviewed some IoT and wearable devices that can monitor older adults. For example, in Wang et al. [7], three categories of wearable technology for monitoring older adults were identified and analyzed: indoor positioning, real-time sign monitoring, and activity recognition. However, the work specialized in identifying only wearable devices that allow the monitoring of intramural positioning. Additionally, Leirós-Rodríguez et al. [8] focused on the review of accelerometers that may be useful in diagnosing balance disorders in older adults, but without considering other types of diseases for the overall population healthcare monitoring. On the other hand, in Rucco et al. [9], devices for monitoring falls in older adults were included and, unlike with this work, discarding those general health monitoring devices, while in Stavropoulos et al. [10] and Tun et al. [11], a more extensive classification was made of the types of reviews focused on monitoring some chronic diseases. Additionally, in Tun et al. [11], a review was presented where the IoT technology was applied in the care of older people. Although Stavropoulos et al. [10] identified wearable devices similar to those described in this work, neither their operation nor their categorization into commercial and research prototypes was raised in their work. In addition, Tun et al. [11] focused their research not on wearable devices but on IoT technology, including devices for smart homes. Most of these reviews focused on healthcare monitoring for older adults did not include a detailed description of the devices identified, nor their grouping by diagnosed disease, nor their classification into commercial and research prototypes. The main differences 
between our work and other research works are three: (1) by the diagnosed diseases considered, (2) by their stage of development reached, and (3) by their FDA-approval level achieved, if any. To remark the differences, a brief comparison here is in order: (1) By the diagnosed diseases considered, Leirós-Rodríguez et al. [8] focused on alterations in balance, Rucco et al. [9] analyzed falls during static and dynamic tasks, and Wang et al. [7] focused on indoor positioning, physical activity tracking, and real-time monitoring of vital signs. Instead, this work considered cardiovascular diseases, respiratory diseases, diabetes, sleep disorders, Parkinson's disease, alcoholism, seizures, and osteoporosis. (2) By the stage of development reached, no distinction between commercial and research prototypes was even suggested in the works of Wang et al. [7], Leirós-Rodríguez et al. [8], Rucco et al. [9], and Stavropoulos et al. [10]. The distinction is vital because only commercial wearable devices can be afforded to provide healthcare to some extent for older adults. (3) By the FDA-approval level achieved, if any, in the works presented by Wang et al. [7], Leirós-Rodríguez et al. [8], Rucco et al. [9], Stavropoulos et al. [10], and Tun et al. [11], no type of FDA approval was proposed. Likewise, others works have identified the monitoring of patients with chronic degenerative diseases [12-16], wearables for promoting physical activities (the deficiency of physical activity has been determined as a crucial influence in developing chronic diseases) [17-19], movement disorders (e.g., Parkinson's disease, freezing of gait) [20-31], development of sensors and wearable technologies [32-36], wearable device use evaluations $[8,10,37-42]$, measurement of biomedical variables and parameters [43-50], and other works have reviewed reviews related to wearables applied to healthcare [51-54]. Therefore, FDA approval for wearable devices is important because it ensures the maximum efficiency and reliability needed as the first step to providing trustworthy healthcare outside the clinic facilities.

Taking into consideration the preamble above and considering the importance of healthcare in the population sector, especially that corresponding to the elderly, the objective was to identify: (1) the physiological (medical) variables of the prevalent diseases in older adults, (2) the characteristics of the wearable devices that best fit the monitoring needs for the healthcare of older adults, and (3) the FDA assessment of wearable devices that are commercially available in the market.

\section{Physiological Variables of Prevalent Diseases in Older Adults}

Once the types of diseases with the most incidents have been identified, it is possible to focus technological development efforts (in remote health monitoring issues) on devices that contain sensors capable of reading the physiological variables impacted by each type of disease. It should be noted that, due to technological limitations, it is not possible to read and monitor all the physiological variables and, therefore, all the identified diseases, still leaving areas of opportunity in terms of monitoring the health status of patients, as is the case of the state of health of cancer patients. Below, a list of the main physiological variables is presented whose monitoring allows intensive observation of patients suffering from some chronic disease. Figure 1 presents a visual representation of the same variables.

\subsection{Heart Rate (HR)}

The heartbeat frequency per minute determines heart rate. This physiological variable is widely used as an indicator of cardiac activity in different physical conditions of the human body, for example, in states of physical activity or inactivity. This variable is increasingly common because it helps monitor users who suffer from health risk conditions and is also used to measure physical performance caused by exercising [55]. HR is a particularly useful parameter in monitoring patients suffering from some cardiovascular disease within the health area. The standard technique to read HR consists of analyzing the time interval between two consecutive $\mathrm{R}$ wave peaks detected (QRS complex). Other data reading techniques that also consider the use of $\mathrm{HR}$ as a metric are ballistocardiography (BCG), phonocardiography (PCG), and impedance cardiography (ICG) [15]. 


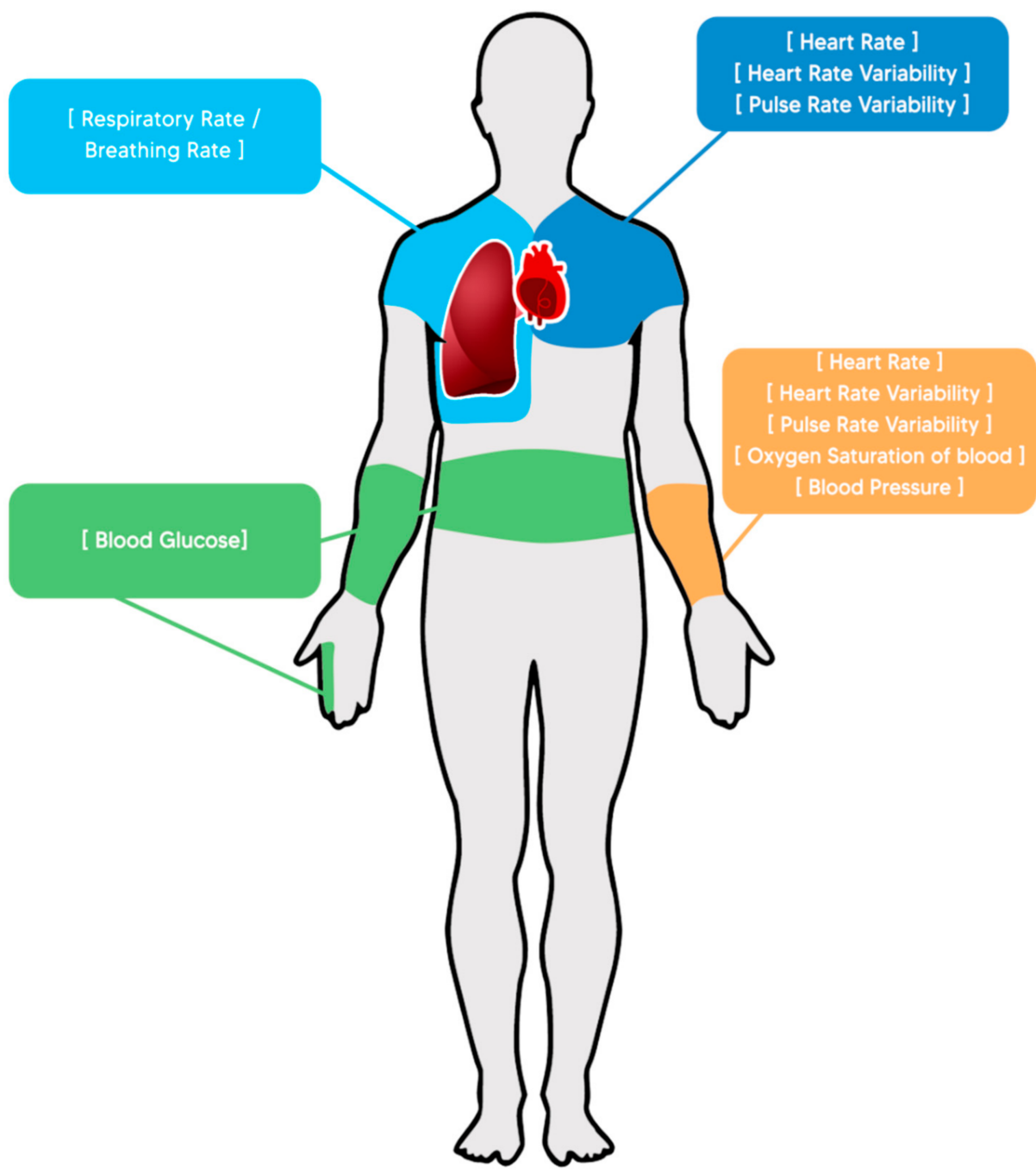

Figure 1. Common physiological variables and the parts of the body to which their readings are normally associated.

\subsection{Heart Rate Variability (HRV)}

HRV is considered a physiological parameter that corresponds to the variation in the time interval between consecutive heartbeats in milliseconds and is a widely studied variable in cardiovascular disease monitoring since it is associated with heart health Generally, high HRV values are associated with a healthy cardiac state, and, therefore, lower probabilities of death are determined. However, HRV may be affected by the gender and age of the patients. In addition, from electrocardiogram (ECG) measurements, the HR and HRV metrics can be estimated as time series of the duration of the cardiac RR intervals [56].

\subsection{Pulse Rate Variability (PRV)}

Verified in numerous studies due to the usefulness of HRV as a diagnostic and clinical research tool, pulse cycle intervals are being used instead of RR intervals as they can be obtained from photoplethysmography (PPG), which is a technique to monitor changes in blood volume in the microvascular bed of tissue. It works from a beam of light (usually green light $(520 \mathrm{~nm})$ ) emitted by the light source (usually diode LED), which falls on the tissue of the human body; most of the light is absorbed, while the rest is reflected. The light reflected by the tissue is captured by the photosensor (receiver), which will generate an electrical signal (voltage) depending on the blood volume variation of the patient. The quality of the measurements provided by this technique depends mainly on 
the light emitter and receiver locations, the characteristics of the patient's tissues, and the quality of the amplifiers and filters. Its use represents a simplification in ambulatory HRV monitoring [57].

\subsection{Respiratory Rate (RR)/Breathing Rate (BR)}

This physiological variable can be used to detect, diagnose or monitor patients affected by chronic diseases such as anxiety, asthma, pneumonia, lung disease, congestive heart failure, drug overdose, or narcotic use. A person's RR is the number of breaths taken per minute. Usually, in adults, an RR at rest between 12 and 20 breaths per minute is considered normal, and an RR at rest is considered abnormal if it is less than 12 or greater than 25 breaths per minute. Some of the techniques under which RR recording is possible are ECG and PPG [58]. The signals obtained by the ECG and PPG have particular characteristics, such as amplitude, period, and frequency. The changes in these characteristics are used to estimate the RR through modulation schemes, such as amplitude modulation (AM), frequency modulation (FM), and baseline wander (BW). However, the presence of each of these modulations depends on each individual. The modulations may appear and disappear over time and vary depending on factors such as pre-existing health conditions, cardiopulmonary system function, gender, age, and body position. For diagnostic and monitoring purposes to provide the relevant information on the patient's heart health, the most accepted frequency range is from 0 (direct current component, DC) to $250 \mathrm{~Hz}$. However, some studies argue that it may be as high as $700 \mathrm{~Hz}$ [59].

\subsection{Oxygen Saturation of the Blood ( $\mathrm{SpO} 2)$}

$\mathrm{SpO} 2$ refers to the amount of oxygen that is saturated in hemoglobin. Healthy adults' good oxygen saturation value is $100 \%$, but this can vary around $5 \%$ without considering a health risk. Some conditions that affect oxygen saturation in the blood vary from circulation problems and heart problems to respiratory problems, anemia, and congenital disabilities. One of the most common ways to measure oxygen saturation is by pulse oximetry. The readings of pulse oximetry reflect the percentage of oxygen present in the blood. Oximetry tests generally use a sensor to read the wavelengths of light reflected from the blood [60]. Pulse oximeters emit two wavelengths of light, red $(660 \mathrm{~nm})$ and near-infrared (near-IR) $(940 \mathrm{~nm})$, from a pair of small light-emitting diodes (LED) located in one arm of the finger probe. Pulse oximetry functioning relies on $\mathrm{O} 2 \mathrm{Hb}$ and $\mathrm{HHb}$ differentially absorbing red and near-infrared (IR) light. It is fortuitous that $\mathrm{O} 2 \mathrm{Hb}$ and $\mathrm{HHb}$ have significant differences in absorption at red and near-IR light, because these two wavelengths penetrate tissues well enough, whereas blue, green, yellow, and far-IR light are significantly absorbed by non-vascular tissues and water [61,62]. The algorithm for calculating SpO2 is based on using the Beer-Lambert law, which is the basis for estimating the percentage relationship of $\mathrm{SpO} 2$ between the oxygenated component of hemoglobin and total hemoglobin (made up of oxyhemoglobin and deoxyhemoglobin). The tissue is irradiated at two wavelengths (red and near-IR), and the percentage ratio of SpO2 is calculated from the absorption and reflection of the irradiated light. The calculations can be performed in the time and frequency domain. In the time domain, the changes in amplitude are analyzed to determine the SpO2. However, they are usually accompanied by random noise that causes erroneous estimates. An improvement in the SpO2 calculations can be obtained in the frequency domain, where the amplitudes of the relevant $\mathrm{SpO} 2$ signals stand out from the amplitudes of the random noise. This technique obtains better SpO2 estimate readings from the patient [63]. 


\subsection{Blood Pressure (BP)}

Blood pressure is related to the force of blood exerted against the walls of the arteries. Two numbers describe BP, as in 120/80 mm of mercury ( $\mathrm{mm} \mathrm{Hg}$ ), where the first number, called systolic pressure, measures the pressure in the arteries when the heart beats and pushes blood in the body, whereas the second number, called diastolic pressure, measures the pressure in the arteries when the heart rests between beats. The primary disorder related to an increase in blood pressure is hypertension [64].

\subsection{Blood Glucose (BC)}

$\mathrm{BC}$ is a crucial physiological variable that measures the glucose concentration in the blood or plasma. Glucose is critical as a metabolic substrate for tissue energy production. Pathological conditions that affect glucose production or utilization lead to hypoglycemia. $\mathrm{BC}$ is considered normal if the glucose levels are between 70 and $100 \mathrm{mg} / \mathrm{dl}$ in the fasting state and less than $140 \mathrm{mg} / \mathrm{dl} 2 \mathrm{~h}$ after each meal. For this reason, continuous and effective monitoring of this variable is crucial since it must be interpreted within the clinical setting and concerning counterregulatory hormonal responses and intermediate metabolites. The leading disease related to blood glucose levels is diabetes [65].

\subsection{Other Physiological Variables}

The physiological variables analyzed in this work were restricted to only those detected by commercially available wearables or by promising research prototypes that could be introduced relatively soon into the market. Therefore, physiological variables (such as lactate, vitamins, or uric acid) that the available wearable devices cannot measure were excluded for analysis.

\section{Methods}

This paper is a review of sensor technologies from the IoT perspective to determine if it is possible to monitor specific diseases using wearable devices and provide healthcare to older adults. For this review, due to its clarity and methodological depth, the PRISMA statement $[66,67]$ was used only to organize and present the review more clearly.

Inclusion and exclusion criteria. A total of 24,615 results were obtained from all the databases. A total of 23 records were removed within the 24,615 results obtained. However, this search was refined to discard all of those published before 2010, leaving 24,592 papers. Below, we describe the inclusion and exclusion criteria.

Inclusion criteria: Papers related to (1) healthcare in older adults, (2) deadly, chronic, or degenerative disease, (3) commercial and non-commercial wearable devices, (4) healthcare monitoring, (5) IoT wearable devices, and (6) FDA-approved medical devices published from 2010 to 2021 were included.

Exclusion criteria: Papers that (1) were not written in English, (2) were not peerreviewed, (3) were letters and reports, and (4) not primary studies were excluded.

Information Sources. The keywords found in the research questions could be grouped and classified according to their characteristics in the knowledge areas of healthcare and computing technology. These areas determined the specialty of the scientific digital library chosen as the source of information. For the area of healthcare, the digital scientific libraries considered were PubMed, Medline Plus, Clinical Trials, and Nice.org.uk, whereas for the area of computing technology, the digital libraries considered were IEEE Xplore, Science Direct, Hindawi, MDPI, Springer Link, Wiley Online Library, and Inderscience. These libraries were chosen because of the good results from pilot searches obtained from the federated search engine Google Scholar. From these primary sources of information, the relevant studies were extracted by submitting search queries to the corresponding search engines of each digital library. The searches were performed from January to June 2021. 
Search Strategy. The search strategy combined keywords using Boolean-like connectives to narrow the results. The search keywords were drawn from the key concepts shaping the research questions. The search strategy derived a series of intermediate searches whose application finally led to answering the research question. Intermediate searches were ordered to find the search terms to be used in subsequent queries:

1. The main global deadly, chronic, or degenerative diseases for older people

2. The physiological variables used in diagnosed diseases

3. The sensors and biosensors that measure those physiological variables

4. The consumer wearable devices available in the market that use those sensors

5. The wearable devices that were available or not in the market

6. The FDA-approved commercial wearable devices available

7. The remote healthcare monitoring devices.

Queries 1 and 2 were applied to the medical databases. Query 1 led to the following search expression, which used adjacent search terms combined with AND and OR connectives:

'main global disease' AND ('deadly disease' OR 'chronic disease' OR 'degenerative disease') AND ('older people' OR 'elderly people' OR ‘aged population')

The analysis of the results showed that the relevant search terms were the physiological variables referred to in the older adults' diagnosed diseases. Query 2 included these search terms in a search expression whose execution produced new results related to physiological variables. Similarly, as the results of each of the queries listed before produced new search terms, the results were progressively expanded until reaching those that were relevant to this study.

The results at the last stage comprised those wearable devices containing sensors (biosensors) that can diagnose some major diseases in older people, including devices that can be used for remote monitoring. The included wearable devices could be either commercial or non-commercial, and in the former case, they could be either FDA-approved or not.

Selection process. Relevant papers were selected by title and abstract for a thorough analysis by three experts. The experts extracted the paper's information in seven categories: brand, model, target (disease), device type, functioning, sensors (used), and FDA status. After concluding the analysis, 24241 papers were excluded.

By reviewing the research objectives and questions of the screened papers, it was determined that 351 papers were of interest for a more detailed analysis of their content, excluding 295 papers. In addition, due to their features and detailed reviews of wearables useful for remote monitoring of health parameters in older adults, 56 articles were selected to be included in this work. In Figure 2, a PRISMA diagram represents the search strategy implemented to include the revisions presented in this document.

Finally, 56 articles were downloaded in total: IEEE (19), other sources (9), ScienceDirect (7), Nice.org.uk (7), MDPI (6), Springer Link (4), and Wiley (4).

Data collection and analysis. Once the selection of the papers corresponding to the primary studies concluded, the data contained in their texts were extracted and inserted in structured tables for analysis. The collected data contained information about commercial wearables and sensors for remote health monitoring. No randomized controlled selection was performed, as the number of wearables found was small (56 items). Three different researchers performed the extraction process. The characteristics of interest for the data collected on the wearable devices were: brand, model, target (disease), device type, functioning, sensors (used), and FDA status. 


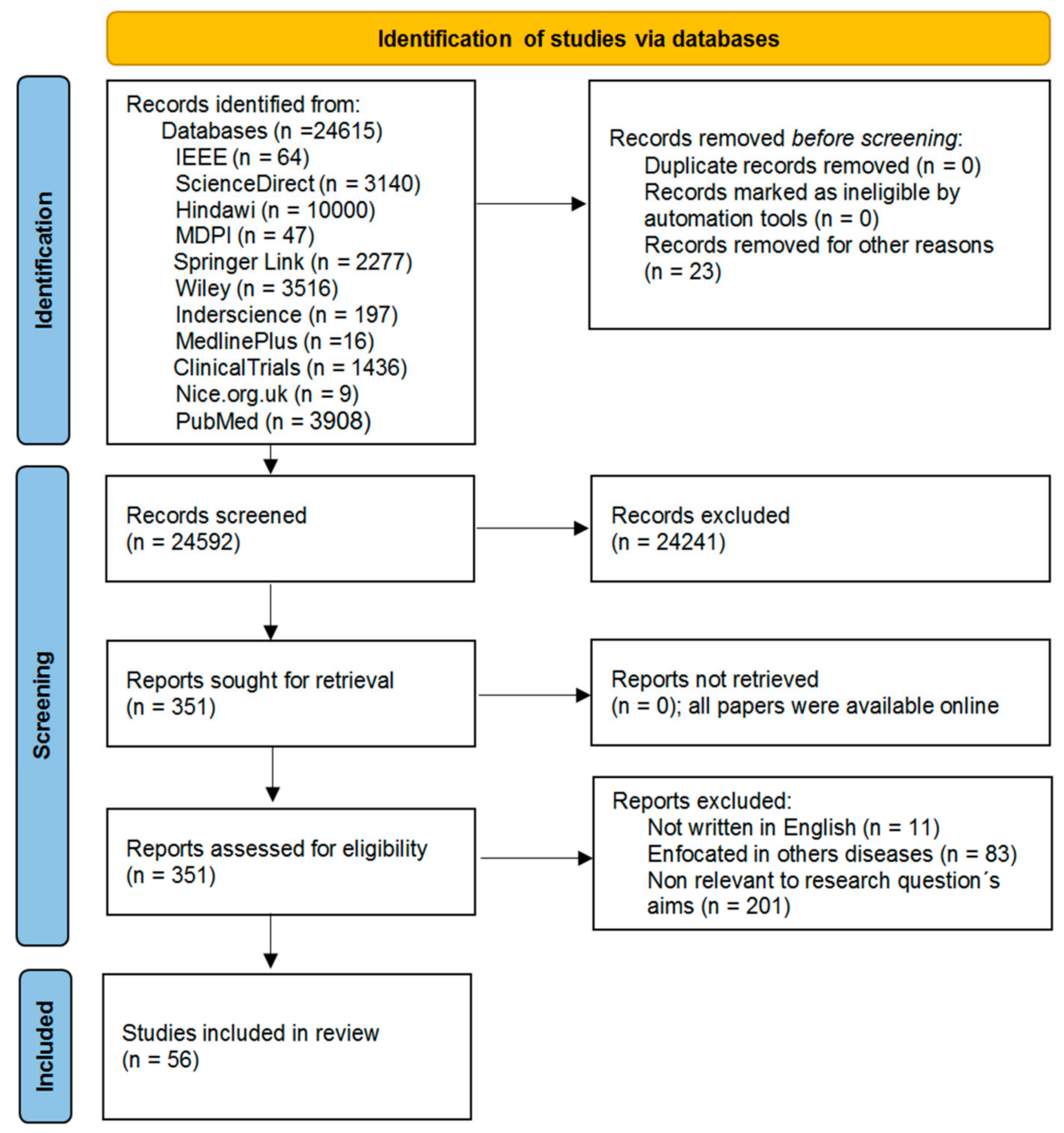

Figure 2. PRISMA flow diagram of the search strategy.

\section{Results}

\subsection{Study Selection}

The records identified through the information sources totaled 24,615. Figure 2 shows the composition of the results grouped by their source database. From this initial record set, 23 records were eliminated. Next, the resulting 24,592 records were screened for relevance analysis of the title and abstract, and 24,241 records were excluded after the screening. The remaining 351 records were assessed for eligibility by examining the relevance of their full-text content. The assessment excluded 295 records from eligibility for several reasons: (i) articles not written in English, (ii) articles focused in other diseases, or (iii) articles not relevant to the research question's aims and objectives. A total of 56 records were finally included as the primary studies after applying the inclusion and exclusion criteria for eligibility.

\subsection{Study Characteristics}

The devices identified were grouped into two large categories: commercial devices and research devices. At the time of writing this paper, among the commercial devices manufactured by technology companies, those already found on the market or with presale status were included. All devices in the prototype phase, reported in scientific and research works but not manufactured yet, were classified as research devices. Below are the reviews for each category of devices, including 24 commercial wearable devices and 32 non-commercial wearable devices. 


\subsubsection{Commercial Wearable Devices}

As previously mentioned, some companies have commercialized different wearable devices whose functions allow monitoring physiological parameters that establish monitoring metrics for one or more types of disease. For this reason, a search was made for commercial devices whose characteristics allow health monitoring in older adults. It should be mentioned that most of these devices do not limit their use to older people. However, due to their capability to obtain data on physiological parameters of interest, they have been classified as suitable for monitoring diseases identified in older adults. In Table 1, a summary of the identified devices is displayed. The columns of this table correspond to the device brand and model, the diagnosed disease, the device type and its operation, a brief list of the sensors that each device uses, and the type of FDA approval.

The table shows that there are already available in the market devices for monitoring physiological parameters needed for the care of patients with some diseases. There are general health monitoring devices that only show basic information for more relaxed health care, as is the case with smartwatches that are functional at a basic-intermediate level. It is necessary to mention that a large share of the devices developed especially for the monitoring of chronic degenerative diseases tend to meet the objective of providing readings in real-time for a better diagnosis and control of symptoms related to the identified diseases.

It is essential to mention that of those commercial devices that were reviewed throughout this work, it was possible to identify, taking into account their characteristics and physical mode of use, the category to which they belong. It should be noted that most of the devices reviewed belonged to the watch category ( $25 \%$ of devices), while the categories with the lowest numbers of devices were finger rings and foot insoles, among others (with $4 \%$ each). On the other hand, it is interesting that $13 \%$ of the devices were classified as intradermal sensors, which shows a growing interest in developing sensors that can be inserted into the human body. In addition, the portable sensor category ( $8 \%$ ) refers to those devices that cannot be categorized as a well-known wearable type such as those discussed before. Moreover, portable sensors may fulfill their functionality in several body parts or be used alone or integrated with other sensors. Figure 3 shows in detail the percentages corresponding to the number of reviewed devices classified by category.

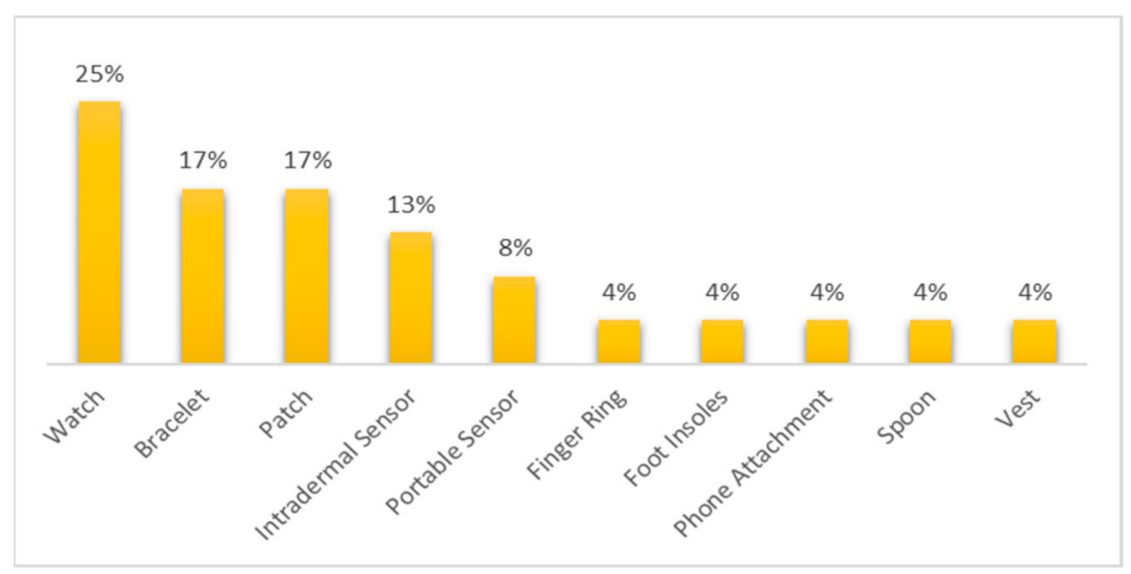

Figure 3. Percentage of reviewed devices classified by wearable category. 
Table 1. Commercial wearables and sensors for remote health monitoring.

\begin{tabular}{|c|c|c|c|c|c|c|}
\hline Brand & Model & Target & Device Type & Functioning & Sensors Used & FDA Status \\
\hline Abbot & Libre 2 [68] & Diabetes & Patch & Reading of blood glucose levels. & $\begin{array}{l}\text { Intradermal Glucose } \\
\text { Sensor }\end{array}$ & Approved (2020) \\
\hline AliveCor $^{\circledR}$ & KardiaMobile [69] & Cardiology & Phone attachment & $\begin{array}{l}\text { Reading the heart rate by positioning } \\
\text { the fingers on the sensors }\end{array}$ & Electrodes & Clear (2014) \\
\hline Apple & Watch 6 [70] & General Purposes & Smart Watch & $\begin{array}{l}\text { Reading the heart rate by positioning } \\
\text { the fingers on the sensors. }\end{array}$ & $\begin{array}{c}\text { Oximeter, Electrical } \\
\text { Heart Rate Sensor, } \\
\text { Optical Heart Rate } \\
\text { Sensor, Accelerometer, } \\
\text { Gyroscope }\end{array}$ & $\begin{array}{l}\text { ECG Approved } \\
\text { (2018)/Oximeter not } \\
\text { Approved }\end{array}$ \\
\hline BACtrack $^{\circledR}$ & Skyn $^{\mathrm{TM}}[71]$ & Alcoholism & Bracelet & Measurement of alcohol levels. & - & Not Approved \\
\hline Dexcom & G5 Mobile [72] & Diabetes & Intradermal sensor & $\begin{array}{l}\text { A sensor under the skin measures } \\
\text { glucose levels. } \\
\text { A transmitter attaches to the top of the } \\
\text { sensor and sends the data wirelessly to } \\
\text { a smart device. }\end{array}$ & $\begin{array}{l}\text { Intradermal Glucose } \\
\text { Sensor }\end{array}$ & Approved (2015) \\
\hline Empatica & Embrace 2 [73] & Seizures & Smart Watch & $\begin{array}{l}\text { Use machine learning (ML) to detect } \\
\text { unusual patterns that are possibly } \\
\text { associated with seizures. }\end{array}$ & $\begin{array}{l}\text { EDA Sensor, Peripheral } \\
\text { Temperature Sensor, } \\
\text { 3-Axis accelerometer, } \\
\text { Gyroscope }\end{array}$ & Approved (2018) \\
\hline Empatica & E4 [74] & General Purposes & Bracelet & $\begin{array}{l}\text { It enables researchers to record } \\
\text { physiological signals at home or in the } \\
\text { laboratory. After recording, they can } \\
\text { access the data for deep analysis. }\end{array}$ & $\begin{array}{l}\text { PPG Sensor, 3-axis } \\
\text { Accelerometer, EDA } \\
\text { Sensor (GSR Sensor), } \\
\text { Infrared Thermopile }\end{array}$ & Not Approved \\
\hline Fitbit & Versa $2^{\mathrm{TM}}[75]$ & General Purposes & Smart Watch & $\begin{array}{l}\text { It monitors the heart rate, physical } \\
\text { activity, sleep quality, oxygen } \\
\text { saturation, and body temperature. }\end{array}$ & $\begin{array}{l}\text { 3-axis accelerometer, } \\
\text { optical heart rate } \\
\text { monitor, altimeter, } \\
\text { ambient light sensor, } \\
\text { relative SpO2 sensor, } \\
\text { built-in microphone }\end{array}$ & ECG app cleared (2020) \\
\hline
\end{tabular}


Table 1. Cont.

\begin{tabular}{|c|c|c|c|c|c|c|}
\hline Brand & Model & Target & Device Type & Functioning & Sensors Used & FDA Status \\
\hline Fitbit & Versa $2^{\mathrm{TM}}[75]$ & General Purposes & Smart Watch & $\begin{array}{l}\text { It monitors the heart rate, physical } \\
\text { activity, sleep quality, oxygen } \\
\text { saturation, and body temperature. }\end{array}$ & $\begin{array}{l}\text { 3-axis accelerometer, } \\
\text { optical heart rate } \\
\text { monitor, altimeter, } \\
\text { ambient light sensor, } \\
\text { relative } \mathrm{SpO} 2 \text { sensor, } \\
\text { built-in microphone }\end{array}$ & ECG app cleared (2020) \\
\hline Fitbit & Charge 4 [76] & Cardiology & Smart Watch & $\begin{array}{l}\text { It monitors the heart rate, physical } \\
\text { activity, sleep quality, oxygen } \\
\text { saturation, and body temperature. }\end{array}$ & $\begin{array}{l}\text { 3-axis accelerometer, } \\
\text { optical heart rate } \\
\text { monitor, altimeter }\end{array}$ & Not Approved \\
\hline $\begin{array}{l}\text { Health Care } \\
\text { Originals }\end{array}$ & ADAMM [77] & Asthma & Patch & $\begin{array}{l}\text { It is worn discreetly under clothing. } \\
\text { Follow-up of cough, breathing patterns, } \\
\text { wheezing, heart rate, skin temperature, } \\
\text { and activity level. }\end{array}$ & $\begin{array}{l}\text { Acoustic, HR, } \\
\text { temperature }\end{array}$ & - \\
\hline iRhythm & $\mathrm{Zio}^{\circledR}[78]$ & Cardiology & Patch & $\begin{array}{l}\text { The physiological data collected for a } \\
\text { predefined time interval is sent by mail } \\
\text { to the provider, who generates reports } \\
\text { for the patient and the doctor. }\end{array}$ & ECG & Clear (2021) \\
\hline Medtronic & $\begin{array}{c}\text { Guardian }^{\mathrm{TM}} \text { Sensor } \\
3[80]\end{array}$ & Diabetes & Intradermal sensor & $\begin{array}{l}\text { Once inserted, it remains under the } \\
\text { skin, capturing glucose readings every } \\
5 \text { min, sending them wirelessly to the } \\
\text { MiniMed pump or its Guardian system } \\
\text { so that glucose levels can be seen in } \\
\text { real-time. After } 6 \text { days, it is removed, } \\
\text { discarded, and replaced with a } \\
\text { new sensor. }\end{array}$ & $\begin{array}{l}\text { Intradermal glucose } \\
\text { sensing electrode }\end{array}$ & Approved (2018) \\
\hline
\end{tabular}


Table 1. Cont.

\begin{tabular}{|c|c|c|c|c|c|c|}
\hline Brand & Model & Target & Device Type & Functioning & Sensors Used & FDA Status \\
\hline Orpyx ${ }^{\circledR}$ & Orpyx SI [81] & Diabetic foot & Foot Insoles & $\begin{array}{l}\text { Custom insoles incorporate sensors to } \\
\text { monitor pressure, step count, hours of } \\
\text { wear, and temperature. Provides } \\
\text { real-time audiovisual alerts and } \\
\text { flushing instructions when sustained } \\
\text { high-pressure levels occur. }\end{array}$ & Pressure sensors & Registered \\
\hline Oura & Oura Ring [82] & General Purposes & Finger ring & $\begin{array}{l}\text { It uses a monitoring technology that } \\
\text { collects the heart rate, heart rate } \\
\text { variability, temperature, activity, and } \\
\text { sleep quality from a non-invasive ring. }\end{array}$ & $\begin{array}{l}\text { Body temperature sensor, } \\
\text { optical, infrared sensors, } \\
\text { and a 3D accelerometer } \\
\text { and gyroscope }\end{array}$ & Not Approved \\
\hline Preventice & $\begin{array}{c}\text { BodyGuardian }^{\circledR} \\
\text { Heart [83] }\end{array}$ & Cardiology & Patch & $\begin{array}{l}\text { Small wireless monitor that adheres to } \\
\text { the chest via a disposable strip. The } \\
\text { strip can be repositioned as needed due } \\
\text { to its medical-grade adhesive and } \\
\text { electrode gel and should be replaced } \\
\text { periodically during the monitoring } \\
\text { period. The monitor is returned to the } \\
\text { service provider. }\end{array}$ & Accelerometer, ECG & Clear (2012) \\
\hline Sentio Solutions & Feel [84] & $\begin{array}{l}\text { Emotional/mental } \\
\text { health }\end{array}$ & Bracelet & $\begin{array}{l}\text { A bracelet that monitors physiological } \\
\text { signals throughout the day and learns } \\
\text { to recognize emotional patterns. }\end{array}$ & $\begin{array}{l}\text { EDA, PPG HR, } \\
\text { skin sensor }\end{array}$ & - \\
\hline $\mathrm{Zoll}^{\circledR}$ & LifeVest $^{\circledR}[85]$ & Cardiology & Vest & $\begin{array}{l}\text { It is a portable cardioverter-defibrillator } \\
\text { used by patients at risk of sudden } \\
\text { cardiac death (SCD). It controls } \\
\text { dangerously fast heart rhythms by } \\
\text { applying an electric shock to the heart. } \\
\text { LifeVest WCD is used directly against } \\
\text { the patient's skin. }\end{array}$ & Temperature sensor & Approved (2018) \\
\hline Xiaomi & Mi Band 5 [86] & General Purposes & Bracelet & $\begin{array}{l}\text { It monitors heart rate, physical activity, } \\
\text { sleep quality, oxygen saturation, body } \\
\text { temperature, menstrual cycle. }\end{array}$ & ECG & Not Approved \\
\hline
\end{tabular}


Table 1. Cont.

\begin{tabular}{|c|c|c|c|c|c|c|}
\hline Brand & Model & Target & Device Type & Functioning & Sensors Used & FDA Status \\
\hline Withings & Move ECG [87] & Cardiology & Analog watch & $\begin{array}{l}\text { In } 30 \mathrm{~s} \text {, a medical-grade ECG is ready } \\
\text { by simply pressing the side button and } \\
\text { placing a finger on the bezel. It can } \\
\text { record an ECG with or without a phone } \\
\text { nearby, as the data can be stored on the } \\
\text { watch until the next sync. }\end{array}$ & $\begin{array}{l}\text { Heart rate sensor, } 3 \text {-axis } \\
\text { accelerometer, 3-axis } \\
\text { gyroscope }\end{array}$ & Not Approved \\
\hline Huawei & Band 6 [88] & General Purposes & Smart Watch & $\begin{array}{l}\text { Measurement of oxygen levels in the } \\
\text { blood through the use of LED clusters } \\
\text { and photodiodes. Heart rate } \\
\text { measurement. Sleep } \\
\text { quality monitoring. }\end{array}$ & $\begin{array}{l}\text { Accelerometer, three } \\
\text { electrodes, ECG, } \\
\text { barometric altimeter }\end{array}$ & Not Approved \\
\hline Holter & Stat-On ${ }^{\mathrm{TM}}[89]$ & Parkinson's & Portable sensor & $\begin{array}{l}\text { It is a non-invasive device worn on a } \\
\text { belt that records the user's motor status } \\
\text { at all times of the day. }\end{array}$ & - & - \\
\hline Gyenno & Gyenno Spoon [90] & Parkinson's & Spoon & $\begin{array}{l}\text { By detecting involuntary hand } \\
\text { movements, sensors activate internal } \\
\text { motors that keep the spoon stable, } \\
\text { helping the person eat normally. }\end{array}$ & Accelerometer & - \\
\hline Secmotic & Muvone [91] & Osteoporosis & Portable sensor & $\begin{array}{l}\text { A device that checks if the activity } \\
\text { carried out is appropriate to help } \\
\text { strengthen bones or how much sun is } \\
\text { needed to assimilate adequate amounts } \\
\text { of Vitamin D. }\end{array}$ & - & - \\
\hline
\end{tabular}


Another type of classification is that made from the FDA status of the reviewed devices. For this classification, six statuses were considered: approved, partially approved, clear, partially clear, not approved, and registered. It is worth mentioning that many commercial devices do not have public information regarding their FDA status. It should be noted that $54 \%$ of devices have some FDA approval, while $25 \%$ are on the market without some registration or approval. On the other hand, it was not possible to find official information on the status of at least $21 \%$ of the commercial devices reviewed. Figure 4 shows the percentages corresponding to each group of devices according to their FDA status.

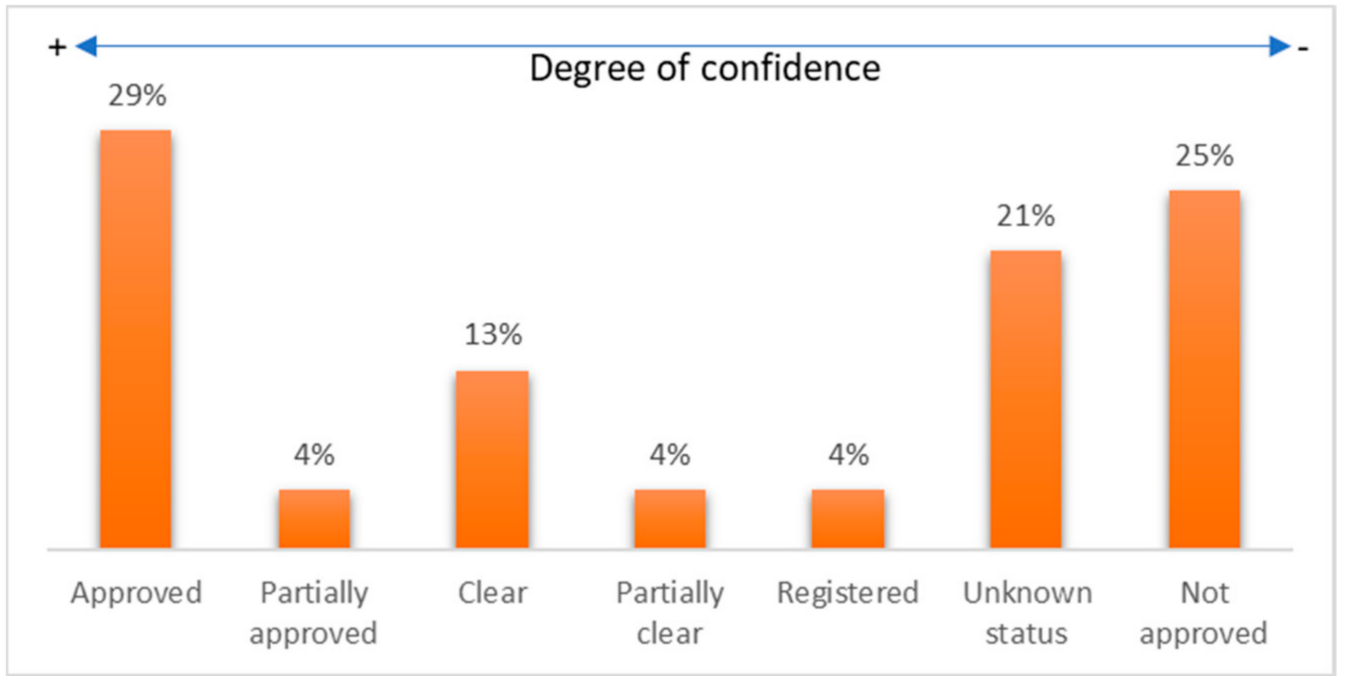

Figure 4. Percentage of reviewed devices classified by their FDA status.

Likewise, it is also essential to identify the diseases for which each device is useful. A count was made of the valuable devices for each identified disease, considering whether or not they have some FDA registration. It should be mentioned that there are devices that can read physiological parameters that allow monitoring more than one type of disease condition. Therefore, some devices appear repeatedly in two or more diseases for cases that meet this condition. Table 2 presents the diseases identified for each device.

The total number of devices for each disease. Figure 5 shows their percentages.

As shown in Figure 5, the development and commercialization of devices are focused on cardiovascular diseases. Thanks to the development of sensors and algorithms that allow reading parameters such as the oxygenation level in the blood and the heart rate, it is possible to design more and better wearable devices at a lower price for this disease category. However, other diseases are more challenging for researchers due to the difficulty of obtaining the necessary readings. An example of this situation is the case of osteoporosis, which needs constant monitoring of a patient's bones, requiring that the relevant sensors to be implanted at the bone level. Sensor implants complicate not only device development but also device placement and maintenance. 
Table 2. The number of reviewed devices that can be used for a given disease.

\begin{tabular}{cccc}
\hline Disease for Which It Can Be Used & FDA Devices & Non-FDA Devices & Total \\
\hline Cardiovascular Diseases & 6 & 7 & 13 \\
General Body Tracking & 2 & 5 & 7 \\
Diabetes & 5 & 0 & 5 \\
Sleep Disorders & 1 & 4 & 5 \\
Parkinson's & 0 & 2 & 2 \\
Alcoholism & 1 & 0 & 1 \\
Seizures & 1 & 0 & 1 \\
Osteoporosis & 0 & 1 & 1 \\
Respiratory Diseases & 0 & 1 & 1 \\
\hline
\end{tabular}

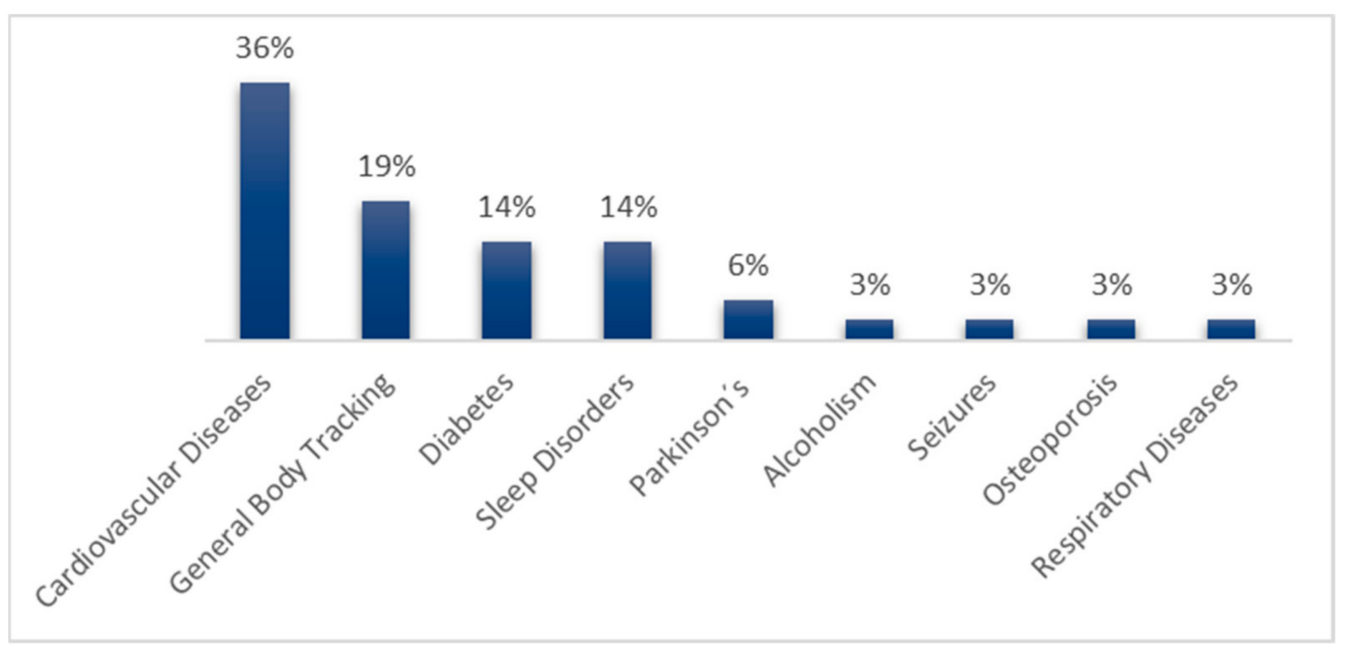

Figure 5. Percentage of reviewed devices useful for a particular disease.

\subsubsection{Non-Commercial Wearable Devices}

As mentioned previously, the technologies in wearable devices that allow the monitoring of physiological parameters are in constant development. Some devices are still in development, while some others are in the prototype phase. Table 3 , shown next, presents the non-commercial devices reported in research articles, whose applicability to monitoring physiological parameters makes them a viable option for follow-up and monitoring of the health status of older adults. The table is organized in columns that describe crucial aspects for health monitoring:

- Target refers to the physiological parameter that the described device can measure.

- Device Type describes the device's category (i.e., watch and bracelet) and the year of publication.

- Functioning is a brief description of how the device works.

- $\quad$ Sensors Used shows the sensors found as part of the device.

- Real-Time Monitoring indicates if the device can monitor the physiological parameter in real-time.

- $\quad$ Elderly User Ready indicates if the device in its proposed version has the optimal characteristics and ease of use for elderly users. 
Table 3. Research wearables and sensors for health monitoring.

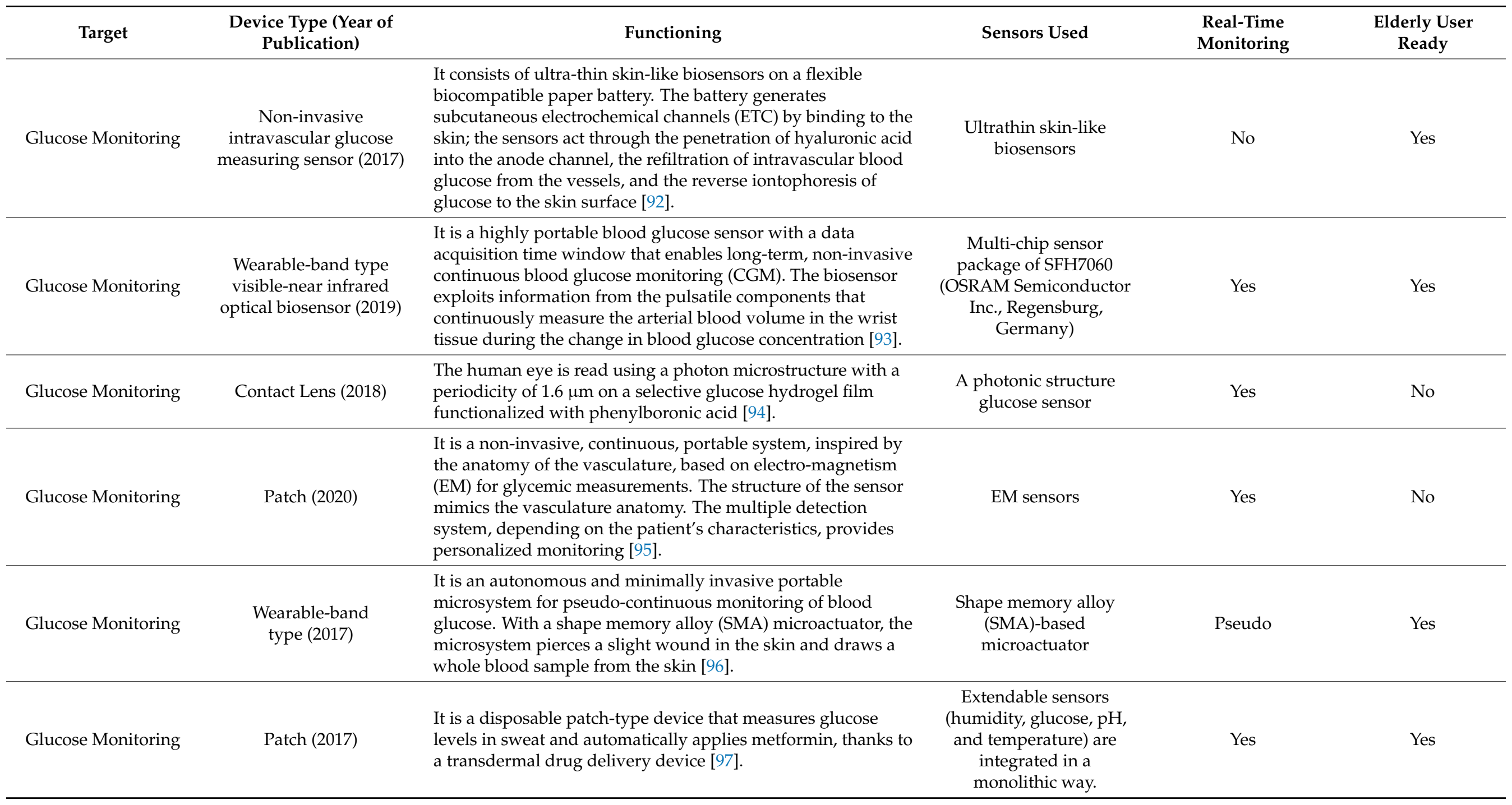


Table 3. Cont.

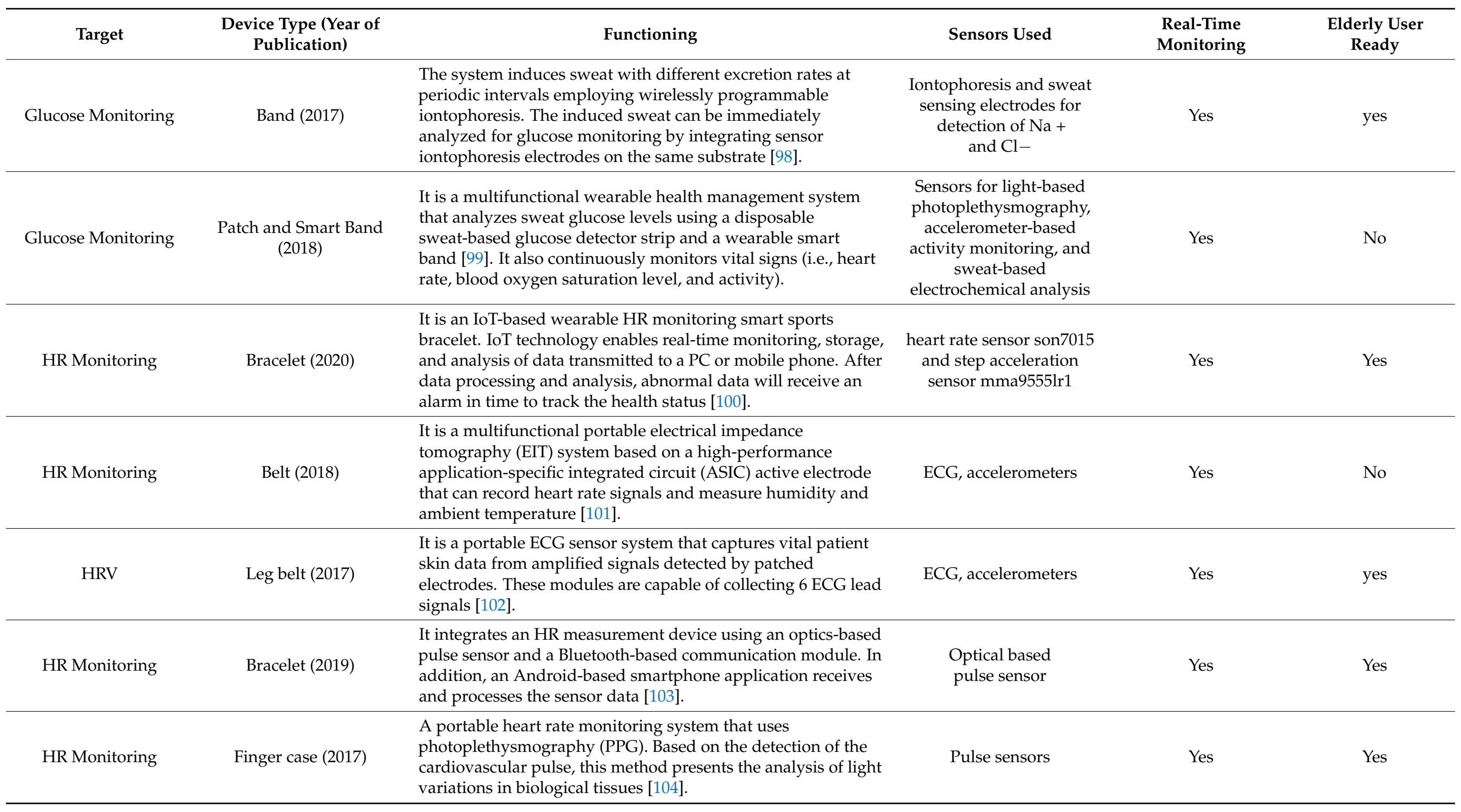


Table 3. Cont.

\begin{tabular}{|c|c|c|c|c|c|}
\hline Target & $\begin{array}{l}\text { Device Type (Year of } \\
\text { Publication) }\end{array}$ & Functioning & Sensors Used & $\begin{array}{l}\text { Real-Time } \\
\text { Monitoring }\end{array}$ & $\begin{array}{l}\text { Elderly User } \\
\text { Ready }\end{array}$ \\
\hline HR Monitoring & Smartwatch (2018) & $\begin{array}{l}\text { It is a prototype that allows monitoring of the heart rate and } \\
\text { the intervals between beats for some subjects. This prototype } \\
\text { was made using the Samsung Gear S3 Smartwatch, with } \\
\text { WebSocket library, nodejs, and JavaScript [105]. }\end{array}$ & Samsung Gear S3 sensors & Yes & No \\
\hline HRV & Armband (2019) & $\begin{array}{l}\text { The device consists of a cuff designed to fit on the upper left } \\
\text { arm that provides } 3 \text { ECG channels based on three pairs of dry } \\
\text { electrodes (without hydrogel) [106]. }\end{array}$ & ECG & Yes & Yes \\
\hline HRV & Ear wear (2019) & $\begin{array}{l}\text { It is a lightweight, portable device that continuously monitors } \\
\text { stress in daily life by measuring electrocardiograms (ECG) and } \\
\text { EEG. The system can be easily worn by hanging it from both } \\
\text { ears [107]. }\end{array}$ & ECG & No & No \\
\hline PRV & (2019) & $\begin{array}{l}\text { It is a portable device that collects PRV values in real-time. The } \\
\text { device includes an amplifier and filter for signal accuracy. An } \\
\text { accelerometer is used to eliminate noise due to motion. This } \\
\text { device can transmit the acquired PPG signal wirelessly with } \\
\text { the use of Wi-Fi technology [108]. }\end{array}$ & Pulse sensors & Yes & \\
\hline PRV & Wristband (2018) & $\begin{array}{l}\text { A portable sensing device capable of continuously monitoring } \\
\text { cardiac movements and parameters on the wrist by using } \\
\text { impedance plethysmography (IPG) technology. The sensor's } \\
\text { design consistently allows getting high-resolution } \\
\text { measurements for up to } 48 \mathrm{~h} \text { [110]. }\end{array}$ & - & Yes & Yes \\
\hline PRV & Wristband (2018) & $\begin{array}{l}\text { A handheld cuffless integrated system utilizes a piezoresistive } \\
\text { tunneling sensor, achieving ultra-high sensitivity to detect } \\
\text { slight wrist artery pressure. After the read, a circuit amplifies } \\
\text { and converts the pulse pressure-induced signal to be wirelessly } \\
\text { transmitted to the cloud for its storage [111]. }\end{array}$ & $\begin{array}{l}\text { Tunneling piezoresistive } \\
\text { sensor }\end{array}$ & Yes & No \\
\hline
\end{tabular}


Table 3. Cont.

\begin{tabular}{|c|c|c|c|c|c|}
\hline Target & $\begin{array}{l}\text { Device Type (Year of } \\
\text { Publication) }\end{array}$ & Functioning & Sensors Used & $\begin{array}{l}\text { Real-Time } \\
\text { Monitoring }\end{array}$ & $\begin{array}{l}\text { Elderly User } \\
\text { Ready }\end{array}$ \\
\hline Respiratory Rate & Fabric (2018) & $\begin{array}{l}\text { It is a smart textile based on a piezoresistive sensor element for } \\
\text { respiratory monitoring [112]. }\end{array}$ & $\begin{array}{l}\text { Silver-plated nylon } \\
\text { knitted fabric }\end{array}$ & Yes & No \\
\hline Respiratory Rate & Stretchable sensor (2019) & $\begin{array}{l}\text { It is an easy-to-use, low-cost, stretchable, and portable RR } \\
\text { sensor that measures respiratory volumetric changes. The } \\
\text { sensor is manufactured using polydimethylsiloxane substrates } \\
\text { (PDMS) and a soft lithography technique for the stretchable } \\
\text { sensor body. An inkjet printing technology creates the } \\
\text { conductive circuit by depositing silver nanoparticles on top of } \\
\text { PDMS substrates that detect inductance fluctuations [113]. }\end{array}$ & RR sensor & Yes & No \\
\hline Respiratory Rate & Armband (2018) & $\begin{array}{l}\text { Respiratory rate is estimated from a cuff ECG using a method } \\
\text { based on variations in the slopes of the QRS and the angle of } \\
\text { the R wave. The estimates are compared with those obtained } \\
\text { from the respiration signal. The cuff includes a pair of dry } \\
\text { electrodes that record the ECG and is designed for long-term } \\
\text { monitoring. [114]. }\end{array}$ & ECG & Yes & No \\
\hline $\begin{array}{l}\text { Oxygen saturation } \\
\text { of blood }\end{array}$ & Finger case (2018) & $\begin{array}{l}\text { The device connects to a cloud gateway to support IoT } \\
\text { applications using an MCU node as a data processor. The data } \\
\text { sent to the cloud can be later accessed online for detailed } \\
\text { analysis [115]. }\end{array}$ & Photodetector & Yes & No \\
\hline $\begin{array}{l}\text { Oxygen saturation } \\
\text { of blood }\end{array}$ & In-ear device (2020) & $\begin{array}{l}\text { It is a device entered into the ear canal for real-time oxygen } \\
\text { saturation measurement in the blood using a } \\
\text { photoplethysmography sensor. It consists of green }(537 \mathrm{~nm}) \text {, } \\
\text { red ( } 660 \mathrm{~nm}) \text {, and infrared ( } 880 \mathrm{~nm} \text { ) emitting diodes, as well as } \\
\text { a photodiode to measure reflected light [116]. }\end{array}$ & $\begin{array}{l}\text { Photoplethysmography } \\
\text { sensor }\end{array}$ & Yes & No \\
\hline $\begin{array}{l}\text { Oxygen saturation } \\
\text { of blood }\end{array}$ & Patch (2018) & $\begin{array}{l}\text { It is a patch-type device that uses green light emitters to } \\
\text { calculate oxygen saturation levels in the blood [117]. }\end{array}$ & $\begin{array}{l}\text { Photoplethysmography } \\
\text { sensor }\end{array}$ & Yes & No \\
\hline
\end{tabular}


Table 3. Cont.

\begin{tabular}{|c|c|c|c|c|c|}
\hline Target & $\begin{array}{c}\text { Device Type (Year of } \\
\text { Publication) }\end{array}$ & Functioning & Sensors Used & $\begin{array}{l}\text { Real-Time } \\
\text { Monitoring }\end{array}$ & $\begin{array}{c}\text { Elderly User } \\
\text { Ready }\end{array}$ \\
\hline $\begin{array}{l}\text { Oxygen saturation } \\
\text { of blood }\end{array}$ & Neck device (2021) & $\begin{array}{l}\text { An integrated PPG sensor (MAX30102 by MAXIM integrated) } \\
\text { housed in a PCB emits red light (650-670 nm) and IR ( } 870-900 \\
\text { nm). Then, the PPG sensor coupled to a photodiode quantifies } \\
\text { light absorption. A three-axis linear accelerometer (LIS2DH12 } \\
\text { by ST Electronics) assesses activity and eliminates motion } \\
\text { artifacts as necessary [118]. }\end{array}$ & $\begin{array}{l}\text { PPG sensor, } \\
\text { accelerometers }\end{array}$ & Yes & No \\
\hline $\begin{array}{l}\text { Oxygen saturation } \\
\text { of blood }\end{array}$ & Finger case (2019) & $\begin{array}{l}\text { It is a portable optical biosensor system that continuously } \\
\text { measures pulse oximetry and heart rate using a } \\
\text { reflectance-based probe [119]. }\end{array}$ & Photodetector & Yes & No \\
\hline Blood pressure & Wrist-watch (2017) & $\begin{array}{l}\text { It is a wristwatch blood pressure monitor to measure blood } \\
\text { pressure by holding the watch against the sternum wall to } \\
\text { detect micro-vibrations of the chest related to the heartbeat. As } \\
\text { the pulse wave travels from the heart to the wrist, an optical } \\
\text { sensor and an accelerometer in the watch allow estimating the } \\
\text { travel time (pulse transit time (PTT) to estimate BP [120]. }\end{array}$ & $\begin{array}{l}\text { Optical based } \\
\text { pulse sensor }\end{array}$ & Yes & Yes \\
\hline Blood pressure & In-ear device (2019) & $\begin{array}{l}\text { A device called eBP measures BP from inside the ear, } \\
\text { minimizing interference with the user's everyday activities } \\
\text { while maximizing their comfort level. Three key components } \\
\text { provide this functionality: (1) a light-based pulse sensor } \\
\text { connected to an inflatable tube placed into the ear, (2) a digital } \\
\text { air pump with a controller, and (3) a BP calculation } \\
\text { algorithm [121]. }\end{array}$ & $\begin{array}{l}\text { Optical based } \\
\text { pulse sensor }\end{array}$ & Yes & No \\
\hline $\begin{array}{l}\text { Blood pressure } \\
\text { and HR }\end{array}$ & Ear wear (2017) & $\begin{array}{l}\text { ECG and PPG-based HR and BP monitor attachable to the ear } \\
\text { for greater usability. It is suggested to place the ECG and PPG } \\
\text { sensors at the back of the ears with the possibility of } \\
\text { integrating them into glasses or headphones [122]. }\end{array}$ & ECG and PPG & Yes & No \\
\hline $\begin{array}{l}\text { Blood pressure } \\
\text { and HR }\end{array}$ & Glasses (2017) & $\begin{array}{l}\text { It is a portable device that monitors the HR at three points on } \\
\text { the user's head. The lens prototype incorporates optical } \\
\text { sensors, processing, storage, and communication components. } \\
\text { The device continuously records the flow of reflected light } \\
\text { intensities from the bloodstream and the inertial measurements } \\
\text { of the wearer's head [123]. }\end{array}$ & $\begin{array}{l}\text { Optical based pulse } \\
\text { sensor }\end{array}$ & Yes & Yes \\
\hline
\end{tabular}


It is worth mentioning that all of the reviewed research devices were developed for healthcare applications, and that more and more developers are choosing to include smaller sensors that allow the construction of more comfortable and less invasive devices. Of course, one of the primary interests in remote healthcare monitoring is to provide these devices with a greater capacity to obtain more and better physiological data and in turn communicate the data in real-time to the various health monitoring software applications to which they are connected.

Additionally, in consideration of their characteristics and modes of use, the reviewed research devices were classified into various wearable categories. Figure 6 shows the percentages of devices assigned to each category.

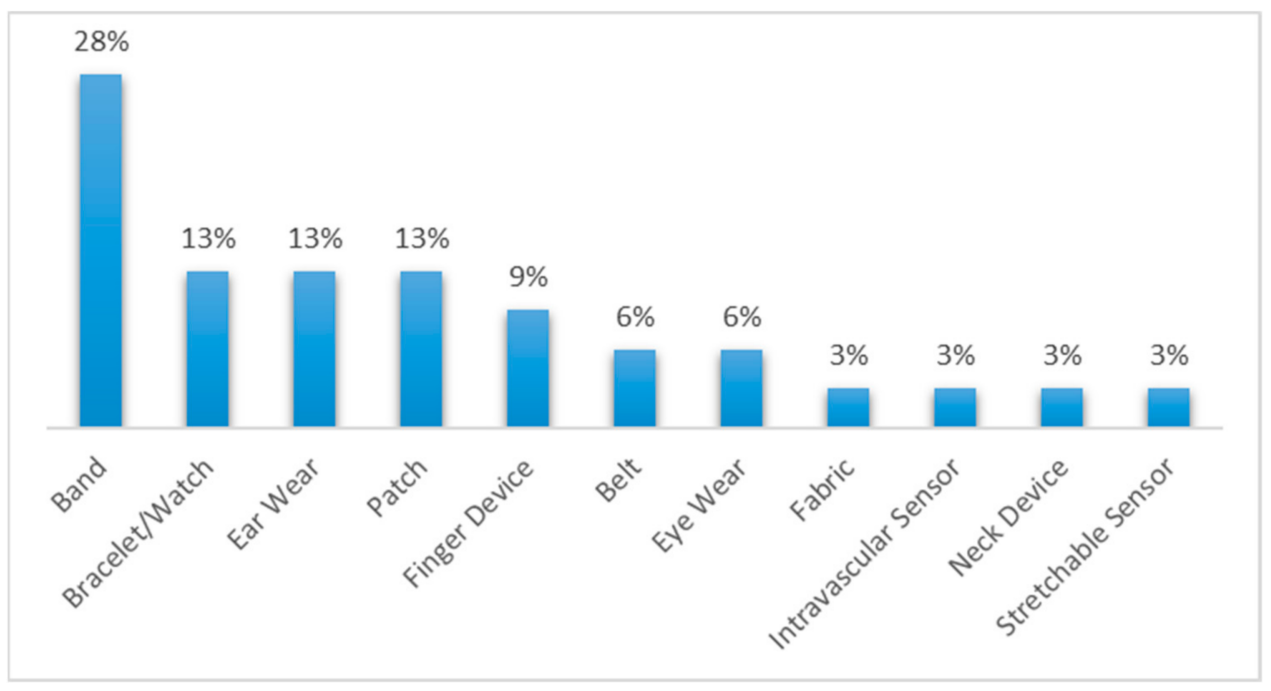

Figure 6. Percentages of reviewed research devices classified by device type.

In turn, in Table 4, the percentages of reviewed devices and sensors that could carry out real-time monitoring were identified. In this work, real-time monitoring devices were identified as those that could transmit data on the body's physiological variables to external devices for processing when they read the data.

Table 4. The number of reviewed devices with real-time monitoring capability.

\begin{tabular}{ccc}
\hline Real-Time Monitoring & No. of Devices & $\%$ \\
\hline Yes & 29 & $91 \%$ \\
No & 3 & $9 \%$ \\
\hline
\end{tabular}

Finally, Table 5 lists the number and percentage of devices that could read some of the most important physiological parameters. Some of the commercial devices were able to measure multiple parameters.

Table 5. The number of devices capable of measuring a specific physiological parameter.

\begin{tabular}{ccc}
\hline Parameter Target & No. of Devices & $\%$ \\
\hline Glucose & 8 & $24 \%$ \\
Heart Rate & 7 & $21 \%$ \\
Oxygen Saturation of Blood & 5 & $15 \%$ \\
Blood Pressure & 4 & $12 \%$ \\
Pulse Rate Variability & 4 & $12 \%$ \\
Heart Rate Variability & 3 & $9 \%$ \\
Respiratory Rate & 3 & $9 \%$ \\
\hline
\end{tabular}


It is worth mentioning that some relevant points were identified as a subject for discussion, mainly the fact that among the devices reviewed in this work, a trend of technological development in commercial devices focused on types of cardiovascular diseases was noted, possibly derived from the current state of sensors available for the measurement of physiological parameters. For this reason, it was easier to measure parameters related to heart conditions, unlike others such as osteoporosis. On the other hand, among the research devices reviewed, it was noted that the most widely used physiological parameters had to do with the measurement of glucose and the heart rate, again, possibly derived from the general state of development of biomedical sensors. This allowed us to identify a relationship between the technological advances in sensors, their target areas, and their impact on trends in the development of manufactured and research devices.

Throughout the preparation of this work, it was possible to identify remarkable data regarding remote health monitoring in older adults. First, it was possible to identify that, of the commercial devices identified as "useful" for monitoring physiological parameters related to diseases, $36 \%$ were mainly focused on cardiovascular diseases, $19 \%$ on general body tracking, $14 \%$ on diabetes, $14 \%$ on sleep disorders, $6 \%$ on Parkinson's, and finally, $3 \%$ each on alcoholism, seizures, osteoporosis, and respiratory diseases. Moreover, it was found that glucose and blood saturation levels, heart and respiratory rates, pulse rate and heart-rate variabilities, and blood pressure are some of the most useful physiological parameters to determine the general user's health condition.

\section{Discussion}

\subsection{Challenges and Trends}

Throughout this work, some challenges were identified due to various factors of technological development. It is important to mention that, despite the tremendous progress that has taken place today in measuring physiological variables, there are still limitations on what can be measured. We see this mainly exemplified by the current difficulties in monitoring and measuring variables concerning difficult access areas such as the bones, lungs, or even the brain. Some of these limitations derive from the size of the components used, the methods for insertion/placement of the sensors inside the human body and their subsequent extraction, and the sensor power supplies, among others. For these reasons, there are still few control and monitoring devices available for many chronic degenerative diseases such as osteoporosis, some types of cancer, and gastrointestinal diseases, among others. These represent challenges to the development and manufacture of devices in three main categories: (1) downsizing of components and sensors, (2) device power supplies, and (3) communication/data transmission methods to access device readings.

The development and conceptualization of wearable devices that fulfill health monitoring functions is a topic of high interest within the scientific community and the business setting. Their applications can range from health care areas in controlled environments to monitoring vital signs and general body conditions with business and military applications in extreme environments. All of this has led to the exploration of new materials, architectures, communication schemes, and other aspects that can change the presentation of wearables and how they work. One of the clearest examples is the development of smart fabrics that include sensors that allow measurements ranging from body temperature to levels of electrical conductivity in the skin. On the other hand, new bio-measurement variables are being explored, including sweat as a parameter to measure metabolites such as lactate and uric acid. Likewise, the advantages of developing devices with "self-repairing" characteristics that allow them to increase their service life or ensure their operation under challenging conditions are also being investigated. Finally, we cannot fail to mention the significant trend toward the development of increasingly compact devices with extended battery life. Technological advances in wearable devices related to healthcare are presented and discussed next. 


\subsection{Emerging Solutions}

Technological development never stops, and the same may be said for the development and manufacture of wearable technology. Nowadays, some trends have been identified that are gaining interest within the scientific community regarding technological development applicable to the healthcare sector. Innovative technological paradigms such as IoT and artificial intelligence are acquiring a fundamental role in the new development proposals for sensors and mobile devices.

IoT is a technological paradigm associated with developing and improving communication schemes between devices that allows connecting devices that are increasingly smaller. Of course, this has sparked interest in, rather than connecting complete wearable devices that incorporate one or more sensors, directly connecting the individual sensors to a communication scheme that allows the collection of physiological data in real-time. Future sensors must be individually capable of transmitting large amounts of data, making them available for more efficient and timely analysis. The increasing demand for sensors in many applications, including healthcare, calls for developing smaller and more efficient batteries so that these sensors can use them individually. In other words, the goal is to achieve wireless communication from each sensor so that it is not entirely necessary for the sensor to be part of a more complex device. Thus, the conceptualization of wearable would change completely. However, achieving wireless communication with such small devices involves other challenges such as energy consumption. Therefore, the development of these independent sensors also depends on constructing more powerful batteries that supply each device opportunely. In the same way, constructing smaller and more efficient chips will allow more efficient energy use [124].

On the other hand, improvements in memory capacity, processor speed and performance, and communication throughput between sensors and applications will facilitate adopting technological paradigms such as AI, which has already been gradually integrated with wearable technology for some years. However, some solutions are still being developed to address the challenge of making individual sensors smarter to ensure that they can self-adapt to the patient's physiological conditions such that their calibration or configuration does not need human intervention [125].

In addition, an increasing interest in developing more and better biosensors to measure biosignals from the human body with a more "invasive" approach should also be noted. This invasive approach allows one, among other things, to perform more reliable readings of some physiological variables such as the level of glucose in the blood [126]. As already mentioned, the idea of building increasingly smaller devices opens up a vast amount of possibilities regarding the use of sensors that can be placed or inserted in parts of the human body without being uncomfortable or obstructive [127]. The development of devices at the molecular level has already begun. It can be said that the combination of all these trends will lead to the development of more efficient, comfortable, and reliable monitoring schemes.

Many technological trends have been observed in the development of healthcare devices, favoring their autonomy, interoperability, embedded intelligence, and usability. However, these features will not be equally enhanced in all devices because their evolution is closely related to their function and user interaction. For example, the ideal device in the case of glucose control would be a stand-alone device, interoperable with data visualization applications, with sufficient built-in intelligence to determine the exact amount of insulin to be administered, and requiring no intervention in its use. Nevertheless, such a device can hardly be built with currently available technology. Autonomy is compromised because it requires incorporating both the insulin reservoir and the battery, which eventually run out. Furthermore, interoperability will be limited by the communication protocols used to send medical data, which are often rapidly rendered obsolete by new needs or new technological developments. In addition, the built-in intelligence to identify glucose patterns rising to critical levels will require increased storage, processing, and energy resources. Finally, usability is fragmented by population preferences, including, for example, aspects such as 
device invasiveness. Invasive devices may be the least demanding of the user's attention, but they are generally not widely accepted, and their autonomy and interoperability are difficult to achieve, as said before. In the future, each technological trend will have a different impact on the design of each wearable device depending on its function and human interaction.

\subsection{Limitations}

The presented review has several limitations:

1. No comparative studies were included regarding the efficacy and reliability of healthcare for older people using FDA-approved wearable devices of clinical equipment grade. Comparisons with FDA-approved devices would shorten the distance in providing the basic infrastructure needed to afford good quality healthcare outside clinic and hospital facilities.

2. Among non-commercial devices, experimental prototypes based on biomarkers were not included in the study. Infectious diseases and malignant neoplasms (cancer), among others, can be diagnosed by biomarker detection. However, promising biomarkerbased biosensor technology is still in the experimental phase. Known as biomarkers, biological molecules found in blood or tissues signal abnormal health conditions and can be detected by immunofluorescence or standard ELISA tests.

3. No comparative studies were considered on the quality of life provided by commercial wearables and clinical-grade scenarios. Although remote healthcare technology is now available, many usability factors remain to be studied before the technology becomes widely accepted. The lack of acceptance of advanced digital technologies by older people and the skills required for their use are significant challenges.

4. No mobile apps were analyzed for healthcare self-management based on the wearable devices presented. The acquisition, processing, and exploration of data obtained from wearables and the notification of relevant related events ultimately require an application for analysis and decision-making. Medical data processing is an important aspect that several wearable device manufacturers have addressed through a cloud storage scheme, where specialized applications can later query the data. Furthermore, literature reviews on cardiovascular diseases [128-133] and diabetes [134-141] have described apps designed for specific diseases that were not addressed here, as they were outside the scope of this research.

5. No studies on the acceptance and skills needed for the appropriate usage of the wearables were considered.

6. No updated FDA-approval information for many wearable devices was readily available online from the manufacturers.

Among the limitations, the lack of FDA-approval grade wearable devices may impede achieving high-quality remote healthcare comparable to the care achieved with corresponding clinical equipment currently available.

\section{Conclusions}

In this work, it was found that, for wearable devices for remote healthcare monitoring for older adults, each biosensor obtains an accurate measurement of the relevant biomedical variables for the timely detection of a particular disease. The most critical biomedical variables identified were glucose, heart rate, oxygen saturation of blood, blood pressure, pulse rate variability, heart rate variability, and respiratory rate. Their importance was determined by the number of wearable devices with sensors and biosensors integrated to detect the corresponding biomedical signals of those diseases. Consequently, only those wearable devices with suitable sensors coordinated by computer applications will allow the extraction of crucial medical information that can be used to adequately monitor specific diseases. Moreover, the characteristics of wearable devices that fit the monitoring needs for the healthcare of older adults were given by their type, which directly influences device usability. In the distribution of wearable devices, the five most frequently cited types in 
the reviewed literature were watches $(25 \%)$, bracelets $(17 \%)$, patches $(17 \%)$, intradermal sensors $(13 \%)$, and portable sensors $(8 \%)$. The question then arises as to whether biosensors integrated into wearable devices can be developed to detect lethal diseases such as malignant neoplasms (various types of cancer) in time, in which case, their state of development as final products for use across broad sectors of society will need to be determined.

In addition, after carrying out the analysis proposed in this work, it should be pointed out that not all major diseases (both due to mortality and morbidity) can be remotely monitored. In general, it can be said that most chronic degenerative diseases can be remotely monitored due to the market availability of devices, including those approved by the FDA. Regarding their medical-grade precision and reliability, the degree of user acceptance of a wearable device was determined by an FDA evaluation. The distribution of wearable devices in the market with an FDA evaluation was as follows: $29 \%$ approved, $4 \%$ partially approved, $13 \%$ clear, $4 \%$ partially clear, $4 \%$ registered, $25 \%$ not approved, and $21 \%$ with unknown status. However, for deadly diseases such as cancer that are difficult to detect in their early stages, both due to their diversity and complexity, only research allows the identification of biochemical markers that reveal the presence of cancer cells. As has been the case with drugs, whose successful approval by the FDA attests to their reliability and efficacy, this prospect of trust will eventually extend to wearable devices. In other words, those devices with FDA approval will eventually gain greater market acceptance because of the high standards of quality in their development that assured their approval.

The scope of this research was limited to wearable biomedical devices that allow obtaining valuable data in the follow-up, monitoring, and management of the health status of older adults. However, devices that can measure other physiological parameters, such as hormonal parameters, were left out. Finally, the main findings in this work were as follows:

- Among the commercial devices reviewed, 25\% belonged to the smartwatch category.

- Among the commercial devices, 54\% had some FDA evaluation (approved, partially approved, cleared, partially cleared, or registered).

- The diagnosed diseases that an FDA-approved wearable device can monitor were cardiovascular diseases, diabetes, general body tracking, sleep disorders, and alcoholism.

- Most of the commercial devices reviewed were devoted to cardiovascular diseases and general body tracking.

- Among the non-commercial wearable devices, those in the band, bracelet/watch, ear wear, and patch category were the most used.

- The physiological parameters that non-commercial wearable devices could monitor were glucose, heart rate, oxygen saturation of blood, blood pressure, pulse rate variability, heart rate variability, and respiratory rate.

Author Contributions: Conceptualization, J.O.O.-A., G.A.-H. and I.M.-C.; Data curation, I.M.-C. and J.R.-C.; Formal analysis, J.R.-C., L.R.-M. and I.M.-C.; Funding acquisition, G.A.-H., I.M.-C. and J.O.O.-A.; Investigation L.R.-M. and J.L.S.-C.; Methodology, J.O.O.-A. and I.M.-C.; Project administration, G.A.-H.; Resources, G.A.-H.; Software, J.O.O.-A., L.R.-M. and J.R.-C.; Supervision, J.L.S.-C. and J.O.O.-A.; Validation, J.O.O.-A., J.R.-C., G.A.-H. and I.M.-C.; Visualization, L.R.-M. and J.R.-C.; Writing-original draft, J.O.O.-A. and J.R.-C.; and Writing-review and editing, G.A.-H., I.M.-C. and J.L.S.-C. All authors have read and agreed to the published version of the manuscript.

Funding: This research was funded by Mexico's National Council of Science and Technology (CONACYT), the Public Secretariat of Education (SEP) through the Sectorial Fund of Research for Education, grant number A1-S-51808, the Council for Scientific Research and Technological Development in Veracruz (COVEICYDET), grant number 12-1806 and the project 52-2016: “Application of Big Data and Semantic Web Techniques to Develop Intelligent Systems", a postdoctoral grant, and a doctoral grant.

Institutional Review Board Statement: Not applicable.

Informed Consent Statement: Informed consent was obtained from all subjects involved in the study.

Data Availability Statement: Not applicable. 
Acknowledgments: This work was supported by Mexico's National Technological Institute (TecNM) and sponsored by both Mexico's National Council of Science and Technology (CONACYT) and the Secretariat of Public Education (SEP) through the PRODEP project (Programa para el Desarrollo Profesional Docente).

Conflicts of Interest: The authors declare no conflict of interest.

\section{References}

1. United Nations Department of Economic and Social Affairs. World Population Ageing 2020: Highlights-Living Arrangements of Older Persons; United Nations: New York, NY, USA, 2021.

2. Prince, M.J.; Wu, F.; Guo, Y.; Gutierrez Robledo, L.M.; O’Donnell, M.; Sullivan, R.; Yusuf, S. The burden of disease in older people and implications for health policy and practice. Lancet 2015, 385, 549-562. [CrossRef]

3. Rizzuto, D.; Melis, R.J.F.; Angleman, S.; Qiu, C.; Marengoni, A. Effect of Chronic Diseases and Multimorbidity on Survival and Functioning in Elderly Adults. J. Am. Geriatr. Soc. 2017, 6, 1056-1060. [CrossRef] [PubMed]

4. Instituto Nacional de Geriatría. Available online: http:/ / www.geriatria.salud.gob.mx (accessed on 13 June 2021).

5. Rizzuto, D.; Bellocco, R.; Kivipelto, M.; Clerici, F.; Wimo, A.; Fratiglioni, L. Dementia After Age 75: Survival in Different Severity Stages and Years of Life Lost. Curr. Alzheimer Res. 2012, 9, 795-800. [CrossRef]

6. Jagger, C.; Matthews, R.; Matthews, F.; Robinson, T.; Robine, J.M.; Brayne, C. The burden of diseases on disability-free life expectancy in later life. J. Gerontol. Ser. A Biol. Sci. Med. Sci. 2007, 62, 408-414. [CrossRef] [PubMed]

7. Wang, Z.; Yang, Z.; Dong, T. A Review of Wearable Technologies for Elderly Care that Can Accurately Track Indoor Position, Recognize Physical Activities and Monitor Vital Signs in Real Time. Sensors 2017, 17, 341. [CrossRef]

8. Leirós-Rodríguez, R.; García-Soidán, J.L.; Romo-Pérez, V. Analyzing the use of accelerometers as a method of early diagnosis of alterations in balance in elderly people: A systematic review. Sensors 2019, 19, 3883. [CrossRef]

9. Rucco, R.; Sorriso, A.; Liparoti, M.; Ferraioli, G.; Sorrentino, P.; Ambrosanio, M.; Baselice, F. Type and location of wearable sensors for monitoring falls during static and dynamic tasks in healthy elderly: A review. Sensors 2018, 18, 1613. [CrossRef]

10. Stavropoulos, T.G.; Papastergiou, A.; Mpaltadoros, L.; Nikolopoulos, S.; Kompatsiaris, I. Iot wearable sensors and devices in elderly care: A literature review. Sensors 2020, 20, 2826. [CrossRef]

11. Tun, S.Y.Y.; Madanian, S.; Mirza, F. Internet of things (IoT) applications for elderly care: A reflective review. Aging Clin. Exp. Res. 2020, 33, 855-867. [CrossRef]

12. Allet, L.; Knols, R.H.; Shirato, K.; de Bruin, E.D. Wearable systems for monitoring mobility-related activities in chronic disease: A systematic review. Sensors 2010, 10, 9026-9052. [CrossRef]

13. Yang, C.C.; Hsu, Y.L. A review of accelerometry-based wearable motion detectors for physical activity monitoring. Sensors 2010, 10, 7772-7788. [CrossRef] [PubMed]

14. Baig, M.M.; GholamHosseini, H.; Moqeem, A.A.; Mirza, F.; Lindén, M. A Systematic Review of Wearable Patient Monitoring Systems-Current Challenges and Opportunities for Clinical Adoption. J. Med. Syst. 2017, 41, 1-9. [CrossRef] [PubMed]

15. Guo, Y.; Liu, X.; Peng, S.; Jiang, X.; Xu, K.; Chen, C.; Wang, Z.; Dai, C.; Chen, W. A review of wearable and unobtrusive sensing technologies for chronic disease management. Comput. Biol. Med. 2021, 129, 104163. [CrossRef] [PubMed]

16. Majumder, S.; Aghayi, E.; Noferesti, M.; Memarzadeh-Tehran, H.; Mondal, T.; Pang, Z.; Deen, M.J. Smart homes for elderly healthcare-Recent advances and research challenges. Sensors 2017, 17, 2496. [CrossRef] [PubMed]

17. Gal, R.; May, A.M.; van Overmeeren, E.J.; Simons, M.; Monninkhof, E.M. The Effect of Physical Activity Interventions Comprising Wearables and Smartphone Applications on Physical Activity: A Systematic Review and Meta-analysis. Sport. Med. Open 2018, 4, 1-15. [CrossRef]

18. Yen, H.Y.; Chiu, H.L. The effectiveness of wearable technologies as physical activity interventions in weight control: A systematic review and meta-analysis of randomized controlled trials. Obes. Rev. 2019, 20, 1485-1493. [CrossRef]

19. Kirk, M.A.; Amiri, M.; Pirbaglou, M.; Ritvo, P. Wearable Technology and Physical Activity Behavior Change in Adults with Chronic Cardiometabolic Disease: A Systematic Review and Meta-Analysis. Am. J. Health Promot. 2019, 33, 778-791. [CrossRef]

20. Jalloul, N. Wearable sensors for the monitoring of movement disorders. Biomed. J. 2018, 41, 249-253. [CrossRef]

21. Tucker, C.S.; Behoora, I.; Nembhard, H.B.; Lewis, M.; Sterling, N.W.; Huang, X. Machine learning classification of medication adherence in patients with movement disorders using non-wearable sensors. Comput. Biol. Med. 2015, 66, 120-134. [CrossRef]

22. Warmerdam, E.; Hausdorff, J.; Atrsaei, A.; Zhou, Y.; Mirelman, A.; Aminian, K.; Espay, A.J.; Hansen, C.; Evers, L.J.W.; Keller, A.; et al. Long-term unsupervised mobility assessment in movement disorders. Lancet Neurol. 2020, 19, 462-470. [CrossRef]

23. Srinivasan, R.; Ben-Pazi, H.; Dekker, M.; Cubo, E.; Bloem, B. Telemedicine for Hyperkinetic Movement Disorders. Tremor and Other Hyperkinetic Movements. Tremor. Other. Hyperkinetic. Mov. 2020, 10, 1-8. [CrossRef]

24. Espay, A.J.; Bonato, P.; Nahab, F.B.; Maetzler, W.; Dean, J.M.; Klucken, J.; Eskofier, B.M.; Merola, A.; Horak, F.; Lang, A.E.; et al. Technology in Parkinson's disease: Challenges and opportunities. Mov. Disord. 2016, 31, 1272-1282. [CrossRef]

25. Maetzler, W.; Domingos, J.; Srulijes, K.; Ferreira, J.J.; Bloem, B.R. Quantitative Wearable Sensors for Objective Assessment of Parkinson's Disease. Mov. Disord. 2013, 28, 1628-1637. [CrossRef]

26. De Lima, A.L.S.; Evers, L.J.; Hahn, T.; Bataille, L.; Hamilton, J.L.; Little, M.A.; Okuma, Y.; Bloem, B.R.; Faber, M.J. Freezing of gait and fall detection in Parkinson's disease using wearable sensors: A systematic review. J. Neurol. 2017, 264, 1642-1654. [CrossRef] 
27. Sweeney, D.; Quinlan, L.R.; Browne, P.; Richardson, M.; Meskell, P.; ÓLaighin, G. A Technological Review of Wearable Cueing Devices Addressing Freezing of Gait in Parkinson's Disease. Sensors 2019, 19, 1277. [CrossRef]

28. Mazzetta, I.; Zampogna, A.; Suppa, A.; Gumiero, A.; Pessione, M.; Irrera, F. Wearable Sensors System for an Improved Analysis of Freezing of Gait in Parkinson's Disease Using Electromyography and Inertial Signals. Sensors 2019, 19, 948. [CrossRef]

29. Pardoel, S.; Kofman, J.; Nantel, J.; Lemaire, E.D. Wearable-Sensor-Based Detection and Prediction of Freezing of Gait in Parkinson's Disease: A Review. Sensors 2019, 19, 5141. [CrossRef]

30. Demrozi, F.; Bacchin, R.; Tamburin, S.; Cristani, M.; Pravadelli, G. Toward a Wearable System for Predicting Freezing of Gait in People Affected by Parkinson's Disease. IEEE J. Biomed. Health Inform. 2020, 24, 2444-2451. [CrossRef]

31. Deb, R.; Bhat, G.; An, S.; Shill, H.; Ogras, U.Y. Trends in Technology Usage for Parkinson's Disease Assessment: A Systematic Review. medRxiv 2021. [CrossRef]

32. Patel, S.; Park, H.; Bonato, P.; Chan, L.; Rodgers, M. A review of wearable sensors and systems with application in rehabilitation. J. Neuroeng. Rehabil. 2012, 9, 1-17. [CrossRef]

33. Martín-Vaquero, J.; Encinas, A.H.; Queiruga-Dios, A.; Bullón, J.J.; Martínez-Nova, A.; González, J.T.; Bullón-Carbajo, C. Review on wearables to monitor foot temperature in diabetic patients. Sensors 2019, 19, 776. [CrossRef]

34. Wu, M.; Luo, J. Wearable Technology Applications in Healthcare: A Literature Review. Online J. Nurs. Inform. Contrib. 2019, 23, 3.

35. Anastasova, S.; Crewther, B.; Bembnowicz, P.; Curto, V.; Ip, H.M.; Rosa, B.; Yang, G.-Z. A wearable multisensing patch for continuous sweat monitoring. Biosens. Bioelectron. 2017, 93, 139-145. [CrossRef]

36. Dang, W.; Manjakkal, L.; Navaraj, W.T.; Lorenzelli, L.; Vinciguerra, V.; Dahiya, R. Stretchable wireless system for sweat pH monitoring. Biosens Bioelectron 2018, 107, 192-202. [CrossRef]

37. Godfrey, A. Wearables for independent living in older adults: Gait and falls. Maturitas 2017, 100, 16-26. [CrossRef]

38. Tedesco, S.; Barton, J.; O'Flynn, B. A review of activity trackers for senior citizens: Research perspectives, commercial landscape and the role of the insurance industry. Sensors 2017, 17, 1277. [CrossRef]

39. Kekade, S.; Hseieh, C.H.; Islam, M.M.; Atique, S.; Mohammed Khalfan, A.; Li, Y.C.; Abdul, S.S. The usefulness and actual use of wearable devices among the elderly population. Comput. Methods Programs Biomed. 2018, 153, 137-159. [CrossRef]

40. Alharbi, M.; Straiton, N.; Smith, S.; Neubeck, L.; Gallagher, R. Data management and wearables in older adults: A systematic review. Maturitas 2019, 124, 100-110. [CrossRef]

41. Teixeira, E.; Fonseca, H.; Diniz-Sousa, F.; Veras, L.; Boppre, G.; Oliveira, J.; Pinto, D.; Alves, A.J.; Barbosa, A.; Mendes, R.; et al. Wearable devices for physical activity and healthcare monitoring in elderly people: A critical review. Geriatrics $2021,6,38$. [CrossRef]

42. Uddin, M.Z.; Khaksar, W.; Torresen, J. Ambient sensors for elderly care and independent living: A survey. Sensors 2018, 18, 2027. [CrossRef]

43. Isravel, D.P.; Arulkumar, D.; Raimond, K.; Issac, B. A novel framework for quality care in assisting chronically impaired patients with ubiquitous computing and ambient intelligence technologies. In Systems Simulation and Modeling for Cloud Computing and Big Data Applications; Peter, J.D., Fernandes, D.L., Eds.; Elsevier: Amsterdam, The Netherlands, 2020; pp. 61-79.

44. Rodbard, D. Continuous Glucose Monitoring: A Review of Successes, Challenges, and Opportunities. Diabetes Technol. Ther. 2016, 18, S23-S213. [CrossRef]

45. Klonoff, D.C.; Ahn, D.; Drincic, A. Continuous glucose monitoring: A review of the technology and clinical use. Diabetes Res. Clin. Pract. 2017, 133, 178-192. [CrossRef]

46. Kim, J.; Campbell, A.S.; Wang, J. Wearable non-invasive epidermal glucose sensors: A review. Talanta 2018, 177, 163-170. [CrossRef]

47. Teymourian, H.; Barfidokht, A.; Wang, J. Electrochemical glucose sensors in diabetes management: An updated review (20102020). Chem. Soc. Rev. 2020, 49, 7671-7709. [CrossRef]

48. Kim, J.; Campbell, A.S.; de Ávila, B.E.F.; Wang, J. Wearable biosensors for healthcare monitoring. Nat. Biotechnol. 2019, 37, 389-406. [CrossRef]

49. Taj-Eldin, M.; Ryan, C.; O'flynn, B.; Galvin, P. A review of wearable solutions for physiological and emotional monitoring for use by people with autism spectrum disorder and their caregivers. Sensors 2018, 18, 4271. [CrossRef]

50. Dias, D.; Cunha, J.P.S. Wearable health devices-Vital sign monitoring, systems and technologies. Sensors 2018, 18, 2414. [CrossRef]

51. Hunkin, H.; King, D.L.; Zajac, I.T. Wearable devices as adjuncts in the treatment of anxiety-related symptoms: A narrative review of five device modalities and implications for clinical practice. Clin. Psychol. Sci. Pract. 2019, 26, e12290. [CrossRef]

52. Dinh, T.; Nguyen, T.; Phan, H.P.; Nguyen, N.T.; Dao, D.V.; Bell, J. Stretchable respiration sensors: Advanced designs and multifunctional platforms for wearable physiological monitoring. Biosens. Bioelectron. 2020, 166, 112460. [CrossRef]

53. Vanegas, E.; Igual, R.; Plaza, I. Sensing systems for respiration monitoring: A technical systematic review. Sensors 2020, 20, 1-84. [CrossRef]

54. Hickey, B.A.; Chalmers, T.; Newton, P.; Lin, C.T.; Sibbritt, D.; McLachlan, C.S.; Clifton-Bligh, R.; Morley, J.; Lal, S. Smart devices and wearable technologies to detect and monitor mental health conditions and stress: A systematic review. Sensors 2021, $21,3461$. [CrossRef]

55. Temko, A. Accurate Heart Rate Monitoring during Physical Exercises Using PPG. IEEE Trans. Biomed. Eng. 2017, 64, 2016-2024. [CrossRef] 
56. Achten, J.; Jeukendrup, A.E. Heart rate monitoring: Applications and limitations. Sport. Med. 2003, 33, 517-538. [CrossRef]

57. Schäfer, A.; Vagedes, J. How accurate is pulse rate variability as an estimate of heart rate variability?: A review on studies comparing photoplethysmographic technology with an electrocardiogram. Int. J. Cardiol. 2013, 166, 15-29. [CrossRef]

58. Birrenkott, D.A.; Pimentel, M.A.F.; Watkinson, P.J.; Clifton, D.A. A Robust Fusion Model for Estimating Respiratory Rate from Photoplethysmography and Electrocardiography. IEEE Trans. Biomed. Eng. 2018, 65, 2033-2041. [CrossRef]

59. Tereshchenko, L.G.; Josephson, M.E. Frequency content and characteristics of ventricular conduction. J. Electrocardiol. 2015, 48, 933-937. [CrossRef]

60. Collins, J.A.; Rudenski, A.; Gibson, J.; Howard, L.; O’Driscoll, R. Relating oxygen partial pressure, saturation and content: The haemoglobin-oxygen dissociation curve. Breathe 2015, 11, 194-201. [CrossRef]

61. Chan, E.D.; Chan, M.M.; Chan, M.M. Pulse oximetry: Understanding its basic principles facilitates appreciation of its limitations. Respir. Med. 2013, 107, 789-799. [CrossRef]

62. Sinex, J.E. Pulse oximetry: Principles and limitations. Am. J. Emerg. Med. 1999, 17, 59-66. [CrossRef]

63. Harvey, J.; Salehizadeh, S.M.; Mendelson, Y.; Chon, K.H. Oxima: A frequency-domain approach to address motion artifacts in photoplethysmograms for improved estimation of arterial oxygen saturation and pulse rate. IEEE Trans. Biomed. Eng. 2018, 66, 311-318. [CrossRef]

64. American Heart Association. What Is Blood Pressure? Available online: https://dc.statelibrary.sc.gov/bitstream/handle/10827/ 25131/DHEC_What_is_High_Blood_Pressure_2017-07.pdf?sequence=1 (accessed on 23 June 2021).

65. Güemes, M.; Rahman, S.A.; Hussain, K. What is a normal blood glucose? Arch. Dis. Child. 2016, 101, 569-574. [CrossRef]

66. Page, M.J.; McKenzie, J.E.; Bossuyt, P.M.; Boutron, I.; Hoffmann, T.C.; Mulrow, C.D.; Shamseer, L.; Tetzlaff, J.M.; Akl, E.A.; Brennan, S.E.; et al. The PRISMA 2020 statement: An updated guideline for reporting systematic reviews. BMJ 2021, 372, n71. [CrossRef]

67. Page, M.J.; McKenzie, J.E.; Bossuyt, P.M.; Boutron, I.; Hoffmann, T.C.; Mulrow, C.D.; Shamseer, L.; Tetzlaff, J.M.; Moher, D. Updating guidance for reporting systematic reviews: Development of the PRISMA 2020 statement. J. Clin. Epidemiol. 2021, 134, 103-112. [CrossRef]

68. Sistema Flash de Monitorización de Glucosa. Available online: https:/ / www.freestylelibre.es/libre/ (accessed on 28 July 2021).

69. KardiaMobile. Available online: https:// www.alivecor.es/kardiamobile (accessed on 28 July 2021).

70. Apple Watch Series 6-Apple (MX). Available online: https://www.apple.com/mx/apple-watch-series-6/ (accessed on 28 July 2021).

71. BACtrack Skyn ${ }^{\mathrm{TM}}$ —The World's 1st Wearable Alcohol Monitor. Available online: https://skyn.bactrack.com/ (accessed on 28 July 2021).

72. G5 mobile Spain. Available online: https://www.dexcom.com/es-ES/g5-mobile-spain (accessed on 28 July 2021).

73. Halford, J.J.; Sperling, M.R.; Nair, D.R.; Dlugos, D.J.; Tatum, W.O.; Harvey, J.; French, J.A.; Pollard, J.R.; Faught, E.; Noe, K.H.; et al. Detection of generalized tonic-clonic seizures using surface electromyographic monitoring. Epilepsia 2017, 58, 1861-1869. [CrossRef]

74. E4 Wristband I Real-Time Physiological Signals I Wearable PPG, EDA, Temperature, Motion Sensors. Available online: https: / / www.empatica.com/research/e4/ (accessed on 28 July 2021).

75. Smartwatch Fitbit Versa 2. Available online: https://www.fitbit.com/global/es/products/smartwatches/versa (accessed on 28 July 2021).

76. Fitbit Charge 4 I Pulsera Avanzada de Salud y Actividad Física. Available online: https://www.fitbit.com/global/es/products/ trackers/charge4 (accessed on 28 July 2021).

77. Health Care Originals-Breathe Easy, Always. Available online: https:/ /healthcareoriginals.com/ (accessed on 28 July 2021).

78. Uninterrupted Ambulatory Cardiac Monitoring. Available online: https://www.irhythmtech.com/ (accessed on 28 July 2021).

79. Sensor Enlite ${ }^{\circledR}$ I Medtronic. Available online: https://www.medtronicdiabeteslatino.com/productos/monitoreo-de-glucosa/ sensor-enliter (accessed on 28 July 2021).

80. Diabetes-Guardian ${ }^{\mathrm{TM}}$ Sensor 3 I Medtronic. Available online: https:/ /www.medtronic.com/us-en/healthcare-professionals / products/diabetes/continuous-glucose-monitoring-systems/guardian-sensor-3.html (accessed on 28 July 2021).

81. About Orpyx SI Sensory Insoles-Orpyx Medical Technologies. Available online: https://www.orpyx.com/about-orpyx-si (accessed on 28 July 2021).

82. Ōura Ring: Accurate Health Information Accessible to Everyone. Available online: https://ouraring.com/ (accessed on 28 July 2021).

83. LISTENS TO THE BEAT—Preventice Solutions. Available online: https://www.preventicesolutions.com/patients/bodyguardian-heart (accessed on 28 July 2021).

84. Biomarkers \& Digital Therapeutics for Mental Health. Available online: https://www.myfeel.co/ (accessed on 28 July 2021).

85. ZOLL LifeVest Wearable Defibrillator I ZOLL Medical Corporation. Available online: https://lifevest.zoll.com/ (accessed on 28 July 2021).

86. Mi Mexico. Available online: https:/ / www.mi.com/mx/mi-smart-band-5/ (accessed on 28 July 2021).

87. ECG Monitor \& Activity Watch-Move ECG I Withings. Available online: https://www.withings.com/ca/en/move-ecg (accessed on 28 July 2021). 
88. HUAWEI Band 6-HUAWEI México. Available online: https://consumer.huawei.com/mx/wearables/band6/ (accessed on 28 July 2021).

89. Akintola, A.A.; van de Pol, V.; Bimmel, D.; Maan, A.C.; van Heemst, D. Comparative Analysis of the Equivital EQ02 Lifemonitor with Holter Ambulatory ECG Device for Continuous Measurement of ECG, Heart Rate, and Heart Rate Variability: A Validation Study for Precision and Accuracy. Front. Physiol. 2016, 7, 391. [CrossRef]

90. GYENNO SPOON. Available online: https:/ / www.gyenno.com/spoon-en.html (accessed on 28 July 2021).

91. Muvone, el Wearable Que Cuida de Tus Huesos. Available online: https://secmotic.com/muvone/ (accessed on 28 July 2021).

92. Chen, Y.; Lu, S.; Zhang, S.; Li, Y.; Qu, Z.; Chen, Y.; Lu, B.; Wang, X.; Feng, X. Skin-like biosensor system via electrochemical channels for noninvasive blood glucose monitoring. Sci. Adv. 2017, 3, e1701629. [CrossRef]

93. Rachim, V.P.; Chung, W.Y. Wearable-band type visible-near infrared optical biosensor for non-invasive blood glucose monitoring. Sens. Actuators B Chem. 2019, 286, 173-180. [CrossRef]

94. Elsherif, M.; Hassan, M.U.; Yetisen, A.K.; Butt, H. Wearable Contact Lens Biosensors for Continuous Glucose Monitoring Using Smartphones. ACS Nano 2018, 12, 5452-5462. [CrossRef]

95. Hanna, J.; Bteich, M.; Tawk, Y.; Ramadan, A.H.; Dia, B.; Asadallah, F.A.; Eid, A.; Kanj, R.; Costantine, J.; Eid, A.A. Noninvasive, wearable, and tunable electromagnetic multisensing system for continuous glucose monitoring, mimicking vasculature anatomy. Sci. Adv. 2020, 6, eaba5320. [CrossRef]

96. Wang, G.; Poscente, M.D.; Park, S.S.; Andrews, C.N.; Yadid-Pecht, O.; Mintchev, M.P. Wearable Microsystem for Minimally Invasive, Pseudo-Continuous Blood Glucose Monitoring: The e-Mosquito. IEEE Trans. Biomed. Circuits Syst. 2017, 11, 979-987. [CrossRef]

97. Lee, H.; Song, C.; Hong, Y.S.; Kim, M.S.; Cho, H.R.; Kang, T.; Shin, K.; Choi, S.H.; Hyeon, T.; Kim, D.-H. Wearable/disposable sweat-based glucose monitoring device with multistage transdermal drug delivery module. Sci. Adv. 2017, 3, e1601314. [CrossRef] [PubMed]

98. Emaminejad, S.; Gao, W.; Wu, E.; Davies, Z.A.; Nyein, H.Y.Y.; Challa, S.; Ryan, S.P.; Fahad, H.M.; Chen, K.; Shahpar, Z.; et al. Autonomous sweat extraction and analysis applied to cystic fibrosis and glucose monitoring using a fully integrated wearable platform. Proc. Natl. Acad. Sci. USA 2017, 114, 4625-4630. [CrossRef] [PubMed]

99. Hong, Y.J.; Lee, H.; Kim, J.; Lee, M.; Choi, H.J.; Hyeon, T.; Kim, D.-H. Multifunctional Wearable System that Integrates Sweat-Based Sensing and Vital-Sign Monitoring to Estimate Pre-/Post-Exercise Glucose Levels. Adv. Funct. Mater. 2018, 28, 1805754. [CrossRef]

100. Xiao, N.; Yu, W.; Han, X. Wearable heart rate monitoring intelligent sports bracelet based on Internet of things. Measurement 2020, 164, 108102. [CrossRef]

101. Wu, Y.; Jiang, D.; Bardill, A.; De Gelidi, S.; Bayford, R.; Demosthenous, A. A high frame rate wearable EIT system using active electrode ASICs for lung respiration and heart rate monitoring. IEEE Trans. Circuits Syst. I Regul. Pap. 2018, 65, 3810-3820. [CrossRef]

102. Hussein, A.F.; Hashim, S.J.; Aziz, A.F.A.; Rokhani, F.Z.; Adnan, W.A.W. A real time ECG data compression scheme for enhanced bluetooth low energy ECG system power consumption. J. Ambient Intell. Humaniz. Comput. 2017, 1-14. [CrossRef]

103. Sani, M.I.; Mutiara, G.A.; Putra, R.S.D.W. Fit-NES: Wearable bracelet for heart rate monitoring. Telkomnika 2019, 17, 392-399. [CrossRef]

104. Raluca Maria, A.; Pasca, S.; Strungaru, R. Heart rate monitoring by using non-invasive wearable sensor. In Proceedings of the 2017 E-Health and Bioengineering Conference, Sinaia, Romania, 22-24 June 2017.

105. Irawan, H.C.; Juhana, T. Heart rate monitoring using IoT wearable for ambulatory patient. In Proceedings of the 11th International Conference on Telecommunication Systems Services and Applications, Lombok, Indonesia, 26-27 October 2017.

106. Lázaro, J.; Reljin, N.; Noh, Y.; Laguna, P.; Chon, K.H. Heart Rate Variability Monitoring Using a Wearable Armband. In Proceedings of the Computing in Cardiology, Singapore, 8-11 September 2019.

107. Ahn, J.W.; Ku, Y.; Kim, H.C. A novel wearable EEG and ECG recording system for stress assessment. Sensors 2019, 19, 1991. [CrossRef]

108. Raj, A.; Karthik, A.K.; Sachin, S.; Sanchana, M.; Ganesan, M. A Wearable Device to Detect Blood Volume Change. In Proceedings of the 5th International Conference on Advanced Computing and Communication Systems, Coimbatore, India, 15-16 March 2019.

109. Kos, M.; Kramberger, I. A Wearable Device and System for Movement and Biometric Data Acquisition for Sports Applications. IEEE Access 2017, 5, 6411-6420. [CrossRef]

110. Schneider, J.; Schroth, M.; Ottenbacher, J.; Stork, W. A novel wearable sensor device for continuous monitoring of cardiac activity during sleep. In Proceedings of the 2018 IEEE Sensors Applications Symposium, Seoul, Korea, 12-14 March 2018.

111. Yeh, K.Y.; Lin, T.H.; Hsieh, Y.Y.; Chang, C.M.; Yang, Y.J.; Lu, S.S. A cuffless wearable system for real-time cutaneous pressure monitoring with cloud computing assistance. In Proceedings of the 2018 International Symposium on VLSI Design, Automation and Test, Hsinchu, Taiwan, 16-19 April 2018.

112. Molinaro, N.; Massaroni, C.; Lo Presti, D.; Saccomandi, P.; Di Tomaso, G.; Zollo, L.; Perego, P.; Andreoni, G.; Schena, E. Wearable textile based on silver plated knitted sensor for respiratory rate monitoring. In Proceedings of the Annual International Conference of the IEEE Engineering in Medicine and Biology Society, Honolulu, HI, USA, 18-21 July 2018.

113. Al-Halhouli, A.; Al-Ghussain, L.; El Bouri, S.; Liu, H.; Zheng, D. Fabrication and evaluation of a novel non-invasive stretchable and wearable respiratory rate sensor based on silver nanoparticles using inkjet printing technology. Polymers 2019, 11, 1518. [CrossRef] 
114. Lázaro, J.; Bailón, R.; Gil, E.; Noh, Y.; Laguna, P.; Chon, K.H. Pilot Study on Electrocardiogram Derived Respiratory Rate Using a Wearable Armband. In Proceedings of the Computers in Cardiology (CinC), Maastricht, The Netherlands; 2018; Volume 45, pp. 1-4.

115. Adiputra, R.R.; Hadiyoso, S.; Hariyani, Y.S. Internet of Things: Low Cost and Wearable SpO2 Device for Health Monitoring. Int. J. Electr. Comput. Eng. 2018, 8, 939-945. [CrossRef]

116. Davies, H.J.; Williams, I.; Peters, N.S.; Mandic, D.P. In-Ear SpO2: A Tool for Wearable, Unobtrusive Monitoring of Core Blood Oxygen Saturation. Sensors 2020, 20, 4879. [CrossRef] [PubMed]

117. Lee, H.; Kim, E.; Lee, Y.; Kim, H.; Lee, J.; Kim, M.; Yoo, H.-J.; Yoo, S. Toward all-day wearable health monitoring: An ultralowpower, reflective organic pulse oximetry sensing patch. Sci. Adv. 2018, 4, eaas9530. [CrossRef] [PubMed]

118. Singh, S.; Kozlowski, M.; Garcia-Lopez, I.; Jiang, Z.; Rodriguez-Villegas, E. Proof-of-concept of a novel neck-situated wearable PPG system for continuous physiological monitoring. IEEE Trans. Instrum. Meas. 2021, 70, 9509609. [CrossRef]

119. Chacon, P.J.; Pu, L.; Da Costa, T.H.; Shin, Y.H.; Ghomian, T.; Shamkhalichenar, H.; Wu, H.C.; Irving, B.A.; Choi, J.W. A Wearable Pulse Oximeter with Wireless Communication and Motion Artifact Tailoring for Continuous Use. IEEE Trans. Biomed. Eng. 2019, 66, 1505-1513. [CrossRef]

120. Carek, A.M.; Conant, J.; Joshi, A.; Kang, H.; Inan, O.T. SeismoWatch: Wearable cuffless blood pressure monitoring using pulse transit time. Proc. ACM Interact. Mob. Wearable Ubiquitous Technol. 2017, 1, 1-16. [CrossRef]

121. Bui, N.; Pham, N.; Barnitz, J.J.; Zou, Z.; Nguyen, P.; Truong, H.; Kim, T.; Farrow, N.; Nguyen, A.; Xiao, J.; et al. eBP: A wearable system for frequent and comfortable blood pressure monitoring from user's ear. In Proceedings of the 25th Annual International Conference on Mobile Computing and Networking, Los Cabos, Mexico, 21-25 October 2019.

122. Zhang, Q.; Zeng, X.; Hu, W.; Zhou, D. A Machine Learning-Empowered System for Long-Term Motion-Tolerant Wearable Monitoring of Blood Pressure and Heart Rate with Ear-ECG/PPG. IEEE Access 2017, 5, 10547-10561. [CrossRef]

123. Holz, C.; Wang, E.J. Glabella. Proceedings of the ACM on Interactive, Mobile, Wearable and Ubiquitous Technologies; ACM PUB27: New York, NY, USA, 2017; Volume 1, pp. 1-23.

124. Xing, N.; Rincon-Mora, G. A Self-Synchronized Maximum-Power-Point Inductively Coupled Wireless Battery Charger for Embedded Microsensors. IEEE J. Emerg. Sel. Top. Ind. Electron. 2021, 2, 297-304. [CrossRef]

125. Amutha, J.; Sharma, S.; Sharma, S.K. Strategies based on various aspects of clustering in wireless sensor networks using classical, optimization and machine learning techniques: Review, taxonomy, research findings, challenges and future directions. Comput. Sci. Rev. 2021, 40, 100376. [CrossRef]

126. Heifler, O.; Borberg, E.; Harpak, N.; Zverzhinetsky, M.; Krivitsky, V.; Gabriel, I.; Fourman, V.; Sherman, D.; Patolsky, F. Clinic-ona-Needle Array toward Future Minimally Invasive Wearable Artificial Pancreas Applications. ACS Nano 2021, 15, 12019-12033. [CrossRef]

127. O'Connell, P.J.; Guilbault, G.G. Future Trends in Biosensor Research. Anal. Lett. 2001, 34, 1063-1078. [CrossRef]

128. Martínez-Pérez, B.; de la Torre-Díez, I.; López-Coronado, M.; Herreros-González, J. Mobile Apps in Cardiology: Review. JMIR Mhealth Uhealth 2013, 1, e15. [CrossRef] [PubMed]

129. Neubeck, L.; Lowres, N.; Benjamin, E.J.; Freedman, S.B.; Coorey, G.; Redfern, J. The mobile revolution-Using smartphone apps to prevent cardiovascular disease. Nat. Rev. Cardiol. 2015, 12, 350-360. [CrossRef]

130. Xie, B.; Su, Z.; Zhang, W.; Cai, R. Chinese Cardiovascular Disease Mobile Apps' Information Types, Information Quality, and Interactive Functions for Self-Management: Systematic Review. JMIR Mhealth Uhealth 2017, 5, e195. [CrossRef] [PubMed]

131. Al-Arkee, S.; Mason, J.; Lane, D.A.; Fabritz, L.; Chua, W.; Haque, M.S.; Jalal, Z. Mobile Apps to Improve Medication Adherence in Cardiovascular Disease: Systematic Review and Meta-analysis. J. Med. Internet Res. 2021, 23, e24190. [CrossRef] [PubMed]

132. Cucciniello, M.; Petracca, F.; Ciani, O.; Tarricone, R. Development features and study characteristics of mobile health apps in the management of chronic conditions: A systematic review of randomised trials. NPJ Digit. Med. 2021, 4, 144. [CrossRef] [PubMed]

133. Spaulding, E.M.; Marvel, F.A.; Piasecki, R.J.; Martin, S.S.; Allen, J.K. User Engagement with Smartphone Apps and Cardiovascular Disease Risk Factor Outcomes: Systematic Review. JMIR Cardio 2021, 5, e18834. [CrossRef]

134. Holmen, H.; Wahl, A.K.; Småstuen, M.C.; Ribu, L. Tailored communication within mobile apps for diabetes self-management: A systematic review. J. Med. Internet Res. 2017, 19, e227. [CrossRef]

135. Wu, X.; Guo, X.; Zhang, Z. The efficacy of mobile phone apps for lifestyle modification in diabetes: Systematic review and meta-analysis. JMIR Mhealth Uhealth 2019, 7, e12297. [CrossRef]

136. Bonoto, B.C.; Piassi Godói, I.; Lovato Pires de Lemos, L.; Godman, B.; Bennie, M.; Diniz, L.M.; Afonso, A.; Junior, G. Efficacy of Mobile Apps to Support the Care of Patients with Diabetes Mellitus: A Systematic Review and Meta-Analysis of Randomized Controlled Trials. JMIR Mhealth Uhealth 2017, 5, e4. [CrossRef]

137. Rossi, M.G.; Bigi, S. mHealth for diabetes support: A systematic review of apps available on the italian market. Mhealth 2017, 3, 16. [CrossRef] [PubMed]

138. Adu, M.D.; Malabu, U.H.; Callander, E.J.; Malau-Aduli, A.E.; Malau-Aduli, B.S. Considerations for the development of mobile phone apps to support diabetes self-management: Systematic review. JMIR Mhealth Uhealth 2018, 6, e10115. [CrossRef] [PubMed]

139. Larbi, D.; Randine, P.; Årsand, E.; Antypas, K.; Bradway, M.; Gabarron, E. Methods and Evaluation Criteria for Apps and Digital Interventions for Diabetes Self-Management: Systematic Review. J. Med. Internet Res. 2020, 22, e18480. [CrossRef] 
140. Brzan, P.P.; Rotman, E.; Pajnkihar, M.; Klanjsek, P. Mobile applications for control and self management of diabetes: A systematic review. J. Med. Syst. 2016, 40, 210. [CrossRef] [PubMed]

141. Martos, M.B.; Velando, A.; Pradas, L.; Suleiman, N.; Cañadas, G.A.; Albendín, L.; Gómez, J.L. Smartphones and Apps to Control Glycosylated Hemoglobin (HbA1c) Level in Diabetes: A Systematic Review and Meta-Analysis. J. Clin. Med. $2020,9,693$. [CrossRef] [PubMed] 